\title{
Constraints on Southern Australian Rainfall Change Based on Atmospheric Circulation in CMIP5 Simulations ${ }^{\text {? }}$
}

\author{
Michael R. GRose AND JAMES S. Risbey \\ CSIRO Oceans and Atmosphere, Hobart, Tasmania, Australia \\ Aurel F. MOISE \\ Bureau of Meteorology Research and Development, Docklands, Victoria, Australia \\ Stacey Osbrough, Craig Heady, Louise Wilson, and Tim Erwin \\ CSIRO Oceans and Atmosphere, Aspendale, Victoria, Australia
}

(Manuscript received 16 February 2016, in final form 20 September 2016)

\begin{abstract}
Atmospheric circulation change is likely to be the dominant driver of multidecadal rainfall trends in the midlatitudes with climate change this century. This study examines circulation features relevant to southern Australian rainfall in January and July and explores emergent constraints suggested by the intermodel spread and their impact on the resulting rainfall projection in the CMIP5 ensemble. The authors find relationships between models' bias and projected change for four features in July, each with suggestions for constraining forced change. The features are the strength of the subtropical jet over Australia, the frequency of blocked days in eastern Australia, the longitude of the peak blocking frequency east of Australia, and the latitude of the storm track within the polar front branch of the split jet. Rejecting models where the bias suggests either the direction or magnitude of change in the features is implausible produces a constraint on the projected rainfall reduction for southern Australia. For RCP8.5 by the end of the century the constrained projections are for a reduction of at least $5 \%$ in July (with models showing increase or little change being rejected). Rejecting these models in the January projections, with the assumption the bias affects the entire simulation, leads to a rejection of wet and dry outliers.
\end{abstract}

\section{Introduction}

Shifts in mean regional rainfall with a warming climate are associated with major impacts on natural and human systems and so are of strong interest to climate change impact and adaptation studies. Quantifying the limits of projected change and the likelihood of reported ranges of change would be valuable information for planning for the coming century.

Rainfall change projections can be of either sign (increase or decrease), and there are some regions where

Supplemental information related to this paper is available at the Journals Online website: http://dx.doi.org/10.1175/JCLI-D-16-0142.s1.

Corresponding author address: Michael R. Grose, CSIRO Oceans and Atmosphere, Castray Esplanade, Battery Point, TAS 7000, Australia.

E-mail: michael.grose@csiro.au the sign of change is very uncertain. The Intergovernmental Panel on Climate Change Fifth Assessment Report (IPCC 2013) reports that southern Australia is projected to get drier through this century, especially in winter. Whetton et al. (2015; Climate Change in Australia) assess this projected drying has high confidence based on various lines of evidence, including studies of physical processes, past trends, and climate model studies. The seasonal and regional signature of the rainfall reduction varies across southern Australia (Hope et al. 2015). Whetton et al. (2015) report a projected change in mean annual rainfall for the high representative concentration pathway (RCP; Van Vuuren et al. 2011) of RCP8.5 of $-26 \%$ to $+4 \%$ for $1986-2005$ to $2081-2100$ (10th-90th percentile range; the median is $-8 \%$ ), with the equivalent for winter of $-32 \%$ to $-2 \%(-17 \%)$. A reliable constraint on the projections could be used to assess the likelihood of little change or a small increase on the one hand or the likelihood of a large decrease on the other. 
Examining the output from a set of global climate models (GCMs) run for a standard set of emissions scenarios has become a common tool for producing climate change projections. A common approach is to examine outputs of the twenty-first century from phase 5 of the Coupled Model Intercomparison Project (CMIP5) multimodel database (Taylor et al. 2012) run for the set of RCPs. However, model collections such as CMIP5 are "ensembles of opportunity" and are not a probabilistic or even statistical sample of uncertainty and may not encompass all possible future change (e.g., Knutti et al. 2010). Also, some or all climate models in an ensemble may be unreliable for some questions (e.g., Risbey and O'Kane 2011). This means that the range of change indicated by an ensemble of models may not be sufficient to produce comprehensive climate projections. In the Australian context, there may be potential to restrict or alter the range of projections if there is sufficient evidence.

Constraints can be thought of as compelling reasons to define limits or bounds or probabilities to projections of the future climate. For climate projections there are three main components of uncertainty: emissions scenario, climate response to those emissions, and internal variability. The relative contribution of these components can be estimated from model ensembles (Hawkins and Sutton 2009, 2011). Using this approach with CMIP5, Whetton et al. (2015) found that response uncertainty in winter rainfall in southern Australia is around $40 \%$ of the total variance for projections to 2050 and beyond (Fig. 1).

Evaluation of the simulation of the current and past climate in terms of mean, variability, and remote drivers of the climate such as the El Niño-Southern Oscillation (ENSO) and the teleconnections to those drivers or recent trends (if attributable) can be used to weight models, including weightings of zero otherwise known as rejection (Tebaldi and Knutti 2007). However, it can be difficult to reliably determine which diagnostics should be used for model acceptance, and the threshold of acceptable model performance can be hard to establish; all models in an ensemble may in fact be below or above such a threshold, so distinguishing a group within them may be misleading (e.g., Knutti et al. 2010). Also, in many cases considering just those models with smaller biases does not produce a reduced spread compared to the whole ensemble (Jun et al. 2008; Reifen and Toumi 2009; Schaller et al. 2011).

Particular insight can come from relationships across an ensemble of models between an aspect of sensitivity and a climate trend that then implies a constraint on possible future change, termed "emergent constraints" [see Flato et al. (2013) and references therein]. In some

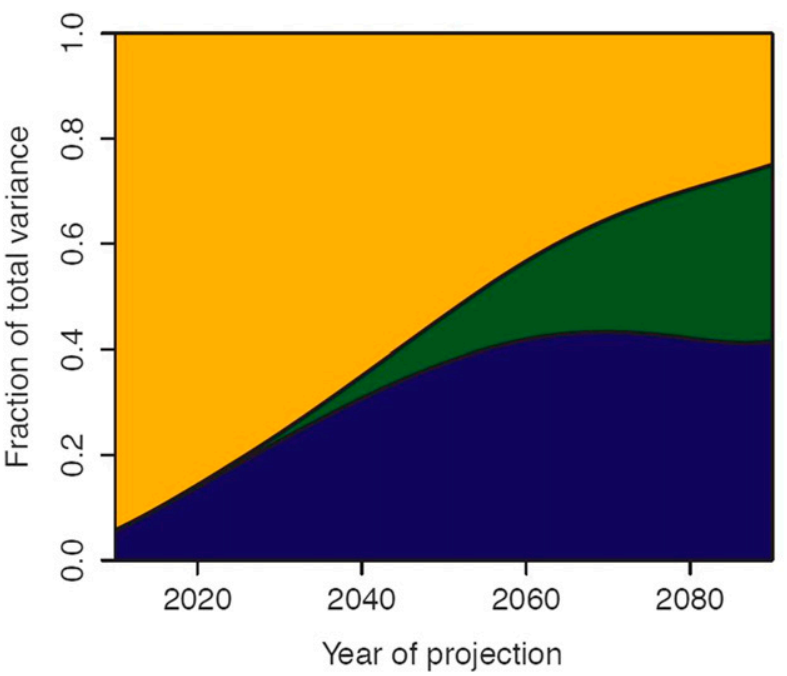

FIG. 1. Fractional contribution of internal variability (orange), scenario (green), and response uncertainty (blue) to total range of projected change in rainfall in southern Australia in winter (JJA) based on 28 CMIP5 models [source: "Climate change in Australia" (Whetton et al. 2015), produced using the methods of Hawkins and Sutton (2009)].

cases it is appropriate to use a single metric of a crucial regional feature to select or weight models and reduce the spread in projections (Schaller et al. 2011). This is most appropriate where a single climate feature has a dominant effect on the regional climate. It may also be possible to use a combination of indices of the most appropriate and related features to isolate a constraint. However, constraints only work where the bias relates to the projection, and the weighting or rejection results in a reduced spread. Here we examine constraints on Australian rainfall projections based on what is likely to be the dominant source of uncertainty: atmospheric circulation features.

Precipitation distribution and variability in midlatitude regions are driven by a range of different circulation factors. These include the stationary wave pattern and its relationship with the jet stream and storm tracks (Hoskins and Valdes 1990). The storm tracks are enhanced by regions of baroclinic instability (Phillips 1951) and vary in association with features like coherent blocking structures (Frederiksen and Webster 1988). As for the midlatitudes generally, precipitation in the southern Australia region is influenced by the preferred regions of baroclinic development in the storm tracks of the Southern Hemisphere (Frederiksen and Frederiksen 2007). Synoptic-scale rainfall in southern Australia is primarily expressed through frontal and cutoff low systems, which vary in association with changes in the storm track and blocking regions (Risbey et al. 2013). In assessing the ability of GCMs to simulate precipitation, and to assess the dominant drivers of changes in the 
mean state of rainfall in future scenarios, it is therefore relevant to examine their simulation of these features (Risbey and Stone 1996; Risbey et al. 2002).

Along with the simulation of the features themselves, models may not simulate a realistic response in rainfall to those features. For example, CMIP5 models do not simulate a realistic relationship between zonal winds and rainfall in southeast Australia (Pepler et al. 2016) or the correct relationship between the subtropical ridge and rainfall (Grose et al. 2015).

In this work we employ a range of diagnostics to quantify the key characteristics of the jets, storm track, baroclinic development, and blocking. We examine the effect of model rejection based on the simulation of these features and particularly look for relationships across the model spread in terms of bias and projected change to determine potential constraints on projections of southern Australian rainfall.

\section{Methods}

We examine model bias and projected change in up to 40 CMIP5 models, with not all data available for each analysis (see Table 1). Two past periods were examined: 1958-80 and 1981-2005, approximately covering either side of the proposed climate "shift" at the end of the 1970s (Frederiksen and Frederiksen 2007), with the first period starting when data are more reliable for the Southern Hemisphere and the second period aligning with the projection's periods. We assess model bias compared to this latter period in reanalysis. We examine projected climate change in the strongest climate change signal case, that of the highest representative concentration pathway (RCP8.5) over the whole twenty-first century calculated as the difference between 1981-2005 and 2075-99. Models and reanalysis were used at their native resolution.

We examine the mean state of atmospheric circulation features relevant to Australian rainfall using standard indices. We use the results from Grose et al. (2015) regarding the subtropical ridge (STR) of high pressure, who used the Drosdowsky (2005) index based on monthly mean sea level pressure (MSLP). The climatological strength and latitude of the major jets are examined using mean 300-hPa zonal wind. This height is used as it shows both the polar front jet and subtropical jet. The wintertime atmospheric blocking over Australia and the Tasman Sea is examined using the Tibaldi and Molteni (1990) index, which uses the gradient of geopotential height at 500- and 1000-500-hPa thickness at defined latitude bands. The index was applied to daily data to quantify the frequency of blocked days per month (days within blocking events of any length). Baroclinic instability as a measure of the potential of where storms can grow is measured using the Phillips instability criterion (e.g., Frederiksen and Frederiksen 2007). The track of where storms and synoptic-scale weather resides in the Southern Hemisphere is measured using the index of Paciorek et al. (2002), which uses the variance of temperature at $500 \mathrm{hPa}$ within the 2.5-10-day band (expanded to a 2-10-day band for use with daily data). January and July are examined in all new analyses, as this illustrates the peaks in the seasonal cycle in most features and avoids the smoothing effects of using three-month seasons.

For the analysis of jets, storm tracks, and Phillips instability, we use the past and future climatology to quantify the peak magnitude and latitude of the zonal mean in boxes over key regions of Southern Hemisphere circulation that are relevant to Australian climate. These boxes are over the regions of greatest magnitude of jets and baroclinic instability in each season and are likely to show the greatest climate change signal. The boxes are over the Australian continent in July and the southern Indian Ocean upstream of Australia in January (marked in Figs. 2 and 3). The upstream Indian Ocean region in January is a key source of weather systems influencing Australia, and the nature of the forced response was found to be similar over Australia (see results section), so we used the peak region to be consistent with the July results. For the blocking indices we use the value of blocking at $150^{\circ} \mathrm{E}$, which is relevant to Australian rainfall, and the longitude of the peak frequency in blocking. Not all models had sufficient data to complete each analysis (see model list in Table 1).

Assessment of bias and projected change in the STR is taken from Grose et al. (2015). Bias in jets, baroclinic instability, and storm tracks is assessed by comparison to the Japanese 55-year Reanalysis (JRA-55; Kobayashi et al. 2015) as well as the European Centre for MediumRange Weather Forecasts (ECMWF) interim reanalysis (ERA-Interim; Dee et al. 2011). The variables needed to perform the analysis of blocking are not available data from ERA-Interim, so instead this section uses JRA-55 and NCEP-NCAR Reanalysis 1 (Kalnay et al. 1996).

We examine the model spread in all models of the bias and projected change in each index and assess where there is a notable linear relationship between the two. We take this relationship as evidence that model bias has an effect on the projected change, and this effect is most marked in the models with the largest bias so these models are candidates for rejection. The threshold for rejecting models is somewhat arbitrary, but for this study we use a threshold where the bias is a standard deviation from the mean. Where there is no relationship, we assume the bias does not have a strong influence on the projection, so no models are rejected even if the bias is large. We examine the rainfall projection for the whole ensemble compared to an ensemble without the identified models. This method assumes 
TABLE 1. CMIP5 models used in the study for each analysis: subtropical ridge (STR), jets, atmospheric blocking, baroclinic instability (bar. inst.), and storm tracks. Models not available for analysis are blank, and models flagged for rejection in rainfall analysis are marked as "Fl." Columns to the right marked with a dot indicate models that are assessed for all features, models that passed all and those that failed two or more tests, and the rainfall projection for southern Australia in January and July as reported in Climate Change in Australia (Whetton et al. 2015).

\begin{tabular}{|c|c|c|c|c|c|c|c|c|c|c|c|}
\hline & Model & STR & Jets & Blocking & Bar. inst. & $\begin{array}{l}\text { Storm } \\
\text { tracks }\end{array}$ & Tested & $\begin{array}{l}\text { Tested, } \\
\text { passed }\end{array}$ & Rejected & $\begin{array}{c}\text { July } \\
\text { projection (\%) }\end{array}$ & $\begin{array}{c}\text { January } \\
\text { projection (\%) }\end{array}$ \\
\hline 1 & ACCESS1.0 & $\bullet$ & $\bullet$ & $\bullet$ & - & • & $\bullet$ & $\bullet$ & & -24.3 & 21.9 \\
\hline 2 & ACCESS1.3 & $\bullet$ & $\bullet$ & $\bullet$ & • & • & $\bullet$ & $\bullet$ & & -23.7 & 3.5 \\
\hline 3 & BCC_CSM1.1 & $\bullet$ & $\bullet$ & $\mathrm{Fl}$ & $\bullet$ & $\bullet$ & $\bullet$ & $\bullet$ & & -15.5 & -12.7 \\
\hline 4 & BCC_CSM1.1(m) & $\bullet$ & • & $\mathrm{Fl}$ & - & - & $\bullet$ & $\bullet$ & & -17.7 & 7.1 \\
\hline 5 & BNU-ESM & $\mathrm{Fl}$ & $\mathrm{Fl}$ & $\mathrm{Fl}$ & $\bullet$ & $\bullet$ & $\bullet$ & & $\bullet$ & -12.4 & 16.0 \\
\hline 6 & CanESM2 & $\bullet$ & $\bullet$ & $\mathrm{Fl}$ & $\bullet$ & $\mathrm{Fl}$ & $\bullet$ & & $\bullet$ & -6.4 & 50.2 \\
\hline 7 & CCSM4 & $\bullet$ & $\bullet$ & & - & & & & & -6.1 & -6.0 \\
\hline 8 & CESM1(BGC) & - & - & & - & & & & & -14.2 & 6.8 \\
\hline 9 & CESM1(CAM5) & $\bullet$ & $\bullet$ & & $\bullet$ & & & & & -4.5 & -11.7 \\
\hline 10 & CMCC-CESM & $\mathrm{Fl}$ & $\bullet$ & $\mathrm{Fl}$ & $\bullet$ & $\mathrm{Fl}$ & $\bullet$ & & $\bullet$ & -21.3 & -31.1 \\
\hline 11 & CMCC-CM & $\bullet$ & $\bullet$ & $\bullet$ & $\bullet$ & $\mathrm{Fl}$ & $\bullet$ & $\bullet$ & & -27.9 & -12.6 \\
\hline 12 & CMCC-CMS & $\bullet$ & $\bullet$ & $\bullet$ & • & $\mathrm{Fl}$ & $\bullet$ & $\bullet$ & & -20.6 & -2.3 \\
\hline 13 & CNRM-CM5 & $\bullet$ & & $\bullet$ & $\bullet$ & $\bullet$ & $\bullet$ & $\bullet$ & & -23.8 & -6.9 \\
\hline 14 & CSIRO Mk3.6.0 & $\mathrm{Fl}$ & $\bullet$ & & $\bullet$ & $\mathrm{Fl}$ & & & $\bullet$ & -20.8 & -41.6 \\
\hline 15 & FGOALS-g2 & $\bullet$ & $\mathrm{Fl}$ & $\mathrm{Fl}$ & $\bullet$ & $\mathrm{Fl}$ & $\bullet$ & & $\bullet$ & -3.7 & 22.5 \\
\hline 16 & FGOALS-s2 & $\bullet$ & $\mathrm{Fl}$ & $\mathrm{Fl}$ & $\bullet$ & $\mathrm{Fl}$ & $\bullet$ & & $\bullet$ & -1.9 & 62.5 \\
\hline 17 & FIO-ESM & $\bullet$ & $\mathrm{Fl}$ & & - & & & & & -9.0 & -6.0 \\
\hline 18 & GFDL CM3 & $\bullet$ & $\mathrm{Fl}$ & $\bullet$ & $\bullet$ & $\mathrm{Fl}$ & $\bullet$ & & $\bullet$ & -32.3 & 2.1 \\
\hline 19 & GFDL-ESM2G & $\bullet$ & $\bullet$ & $\bullet$ & $\bullet$ & $\bullet$ & $\bullet$ & $\bullet$ & & -17.9 & 10.7 \\
\hline 20 & GFDL-ESM2M & $\bullet$ & $\bullet$ & $\bullet$ & • & - & $\bullet$ & $\bullet$ & & -38.1 & -22.2 \\
\hline 21 & GISS-E2-H & $\bullet$ & $\mathrm{Fl}$ & & - & & & & & -2.4 & 8.9 \\
\hline 22 & GISS-E2-H-CC & $\bullet$ & & & & & & & & -19.0 & 26.1 \\
\hline 23 & GISS-E2-R & $\mathrm{Fl}$ & $\mathrm{Fl}$ & & $\bullet$ & & & & $\bullet$ & 4.6 & -12.8 \\
\hline 24 & GISS-E2-R-CC & $\bullet$ & & & & & & & & -2.0 & -6.6 \\
\hline 25 & HadGEM2-AO & $\bullet$ & • & & $\bullet$ & & & & & -23.7 & -5.4 \\
\hline 26 & HadGEM2-CC & $\bullet$ & $\bullet$ & $\mathrm{Fl}$ & $\bullet$ & $\bullet$ & $\bullet$ & $\bullet$ & & -25.1 & 15.9 \\
\hline 27 & HadGEM2-ES & - & - & & • & & & & & -23.7 & -9.8 \\
\hline 28 & INM-CM4.0 & $\bullet$ & $\mathrm{Fl}$ & & $\bullet$ & - & $\bullet$ & $\bullet$ & & -27.1 & -8.3 \\
\hline 29 & IPSL-CM5A-LR & $\mathrm{Fl}$ & $\mathrm{Fl}$ & $\mathrm{Fl}$ & $\bullet$ & $\mathrm{Fl}$ & $\bullet$ & & $\bullet$ & -24.5 & -5.1 \\
\hline 30 & IPSL-CM5A-MR & $\bullet$ & $\bullet$ & $\bullet$ & $\bullet$ & $\mathrm{Fl}$ & $\bullet$ & $\bullet$ & & -35.7 & 22.7 \\
\hline 31 & IPSL-CM5B-LR & $\mathrm{Fl}$ & $\mathrm{Fl}$ & $\bullet$ & - & $\bullet$ & $\bullet$ & & $\bullet$ & 0.3 & -4.2 \\
\hline 32 & MIROC5 & $\bullet$ & $\mathrm{Fl}$ & $\mathrm{Fl}$ & $\bullet$ & $\mathrm{Fl}$ & $\bullet$ & & $\bullet$ & -4.9 & 0.3 \\
\hline 33 & MIROC-ESM & $\mathrm{Fl}$ & $\mathrm{Fl}$ & $\mathrm{Fl}$ & $\bullet$ & $\mathrm{Fl}$ & $\bullet$ & & $\bullet$ & -15.5 & -8.2 \\
\hline 34 & $\begin{array}{l}\text { MIROC-ESM- } \\
\text { CHEM }\end{array}$ & $\mathrm{Fl}$ & $\mathrm{Fl}$ & $\mathrm{Fl}$ & $\bullet$ & $\mathrm{Fl}$ & $\bullet$ & & $\bullet$ & -17.9 & 10.2 \\
\hline 35 & MPI-ESM-LR & $\bullet$ & $\bullet$ & - & $\bullet$ & $\mathrm{Fl}$ & $\bullet$ & $\bullet$ & & -7.4 & -8.7 \\
\hline 36 & MPI-ESM-MR & $\bullet$ & $\bullet$ & $\mathrm{Fl}$ & $\bullet$ & $\mathrm{Fl}$ & $\bullet$ & & $\bullet$ & -30.1 & -3.1 \\
\hline 37 & MRI-CGCM3 & $\bullet$ & - & $\mathrm{Fl}$ & - & $\bullet$ & $\bullet$ & $\bullet$ & & -16.0 & 7.0 \\
\hline 38 & MRI-ESM1 & • & & $\bullet$ & & - & & & & -15.8 & -4.5 \\
\hline 39 & NorESM1-M & $\bullet$ & $\bullet$ & $\bullet$ & - & - & $\bullet$ & $\bullet$ & & -5.0 & 3.6 \\
\hline \multirow[t]{2}{*}{40} & NorESM1-ME & $\bullet$ & $\bullet$ & & $\bullet$ & & & & & 11.2 & -3.5 \\
\hline & Number & 40 & 36 & 27 & 37 & 29 & 27 & 15 & 14 & & \\
\hline
\end{tabular}

that the change in circulation features will be the dominant driver of precipitation change.

\section{Results}

\section{a. Subtropical ridge}

The STR has strengthened and perhaps moved poleward in recent decades, and this seems at least partly forced by greenhouse gases (Nguyen et al. 2013; Timbal and Drosdowsky 2013). Grose et al. (2015) show the STR is projected to strengthen and move south in the future, which is generally associated with drier conditions in southeast Australia. From a comparison of recent 55-year trends in models with that in Bureau of Meteorology observations and NCEP-NCAR Reanalysis 1, Grose et al. (2015) find that the STR intensification is underestimated in all models, and this implies the future 
a. 300hPa UA, 1981-2005 Jul, JRA55
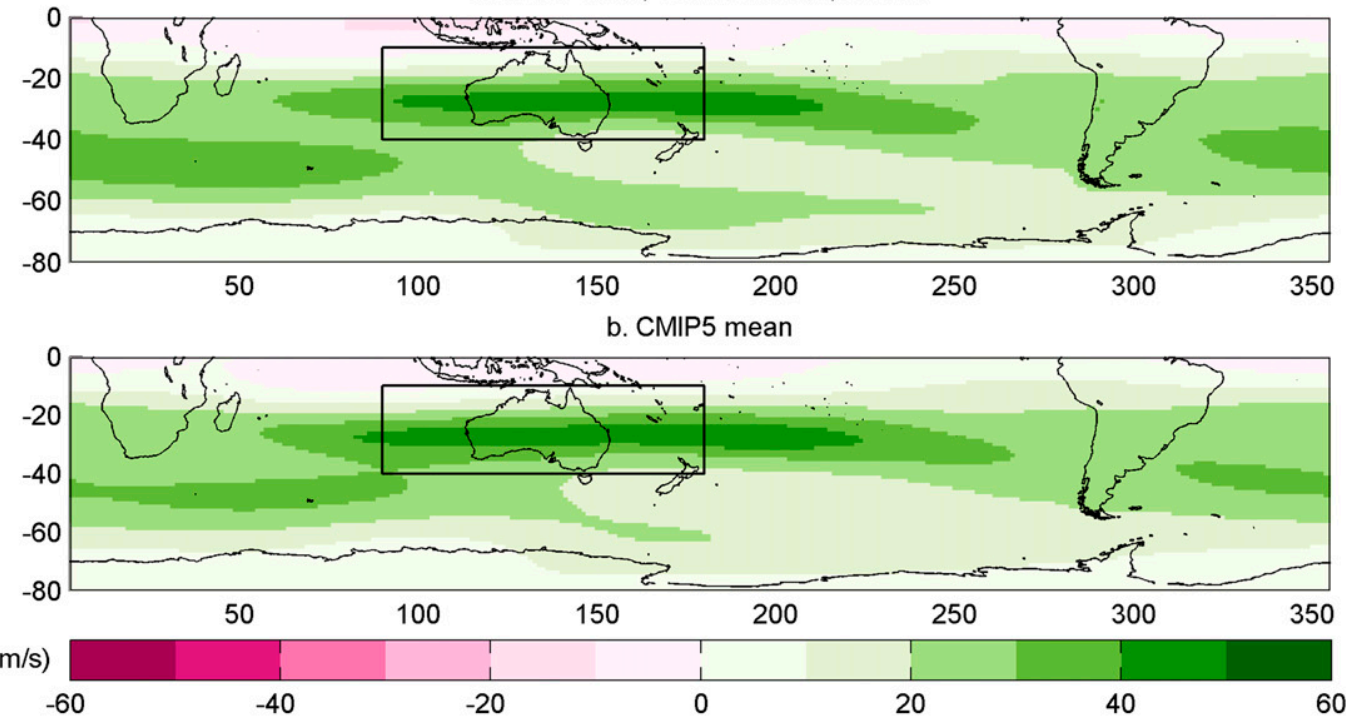

c. Model mean change

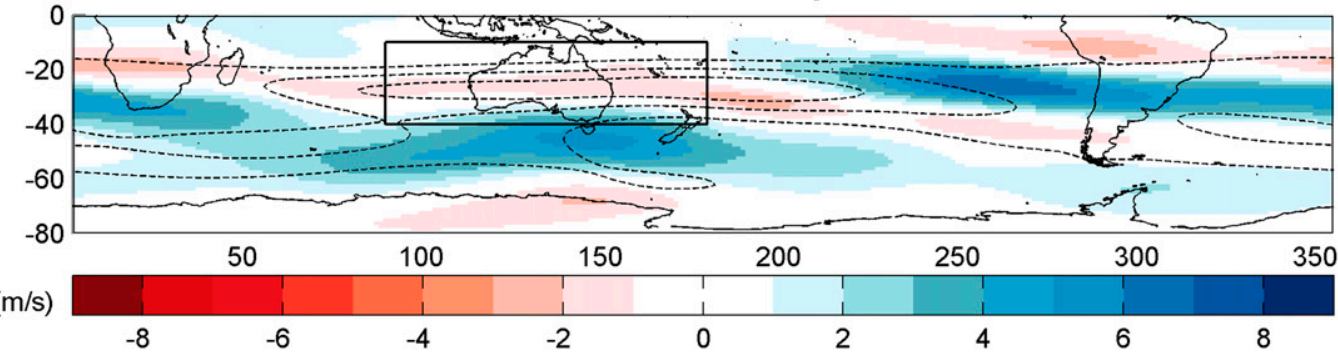

d. Jet strength

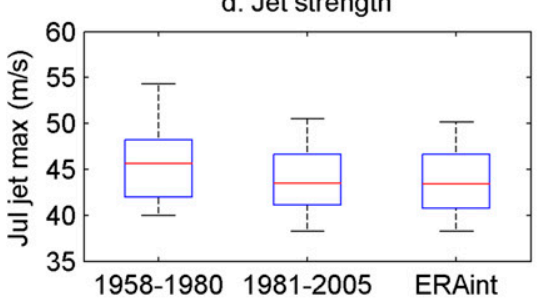

f. Jet strength bias and change
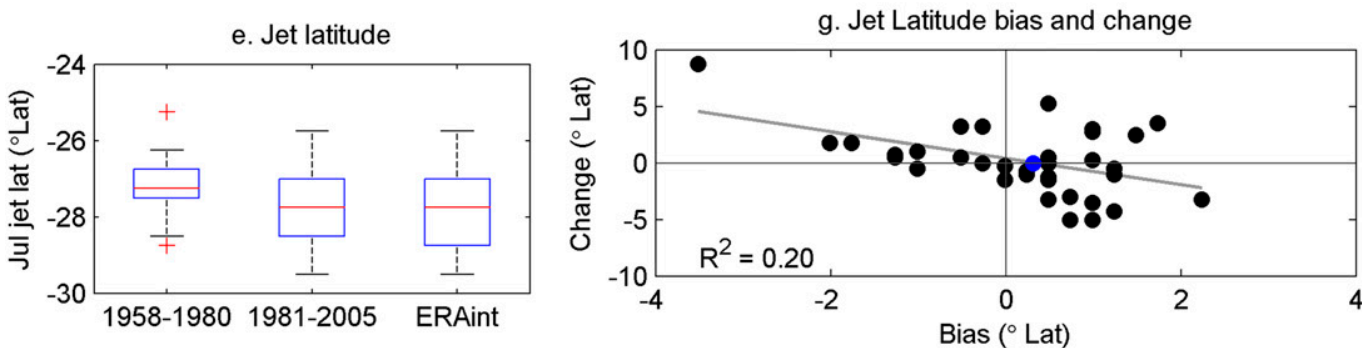

FIG. 2. Mean 300-hPa zonal wind in July: (a) JRA-55 in 1981-2005; (b) CMIP5 mean in 1981-2005; (c) multimodel change from 1981-2005 to 2075-99, where dashed lines are the 20,30 , and $40 \mathrm{~m} \mathrm{~s}^{-1}$ contours in the model mean in the current climate; (d) box plot of July strength in zonal mean of box in each year in JRA-55 in 1958-80, JRA-55 in 1981-2005, and ERA-Interim in 1981-2005 (red plus symbols indicate outliers); (e) as in (d), but for latitude; (f) results from 36 CMIP5 models in the zonal mean of the box in the climatology, with bias in 19812005 and projected change to 2075-2099 and where red are flagged models, others are black, and the blue dot shows the bias between ERA-Interim and JRA-55 on the $x$ axis; (g) as in (f), but for latitude. 
a. $300 \mathrm{hPa}$ UA, 1981-2005 Jan, JRA55
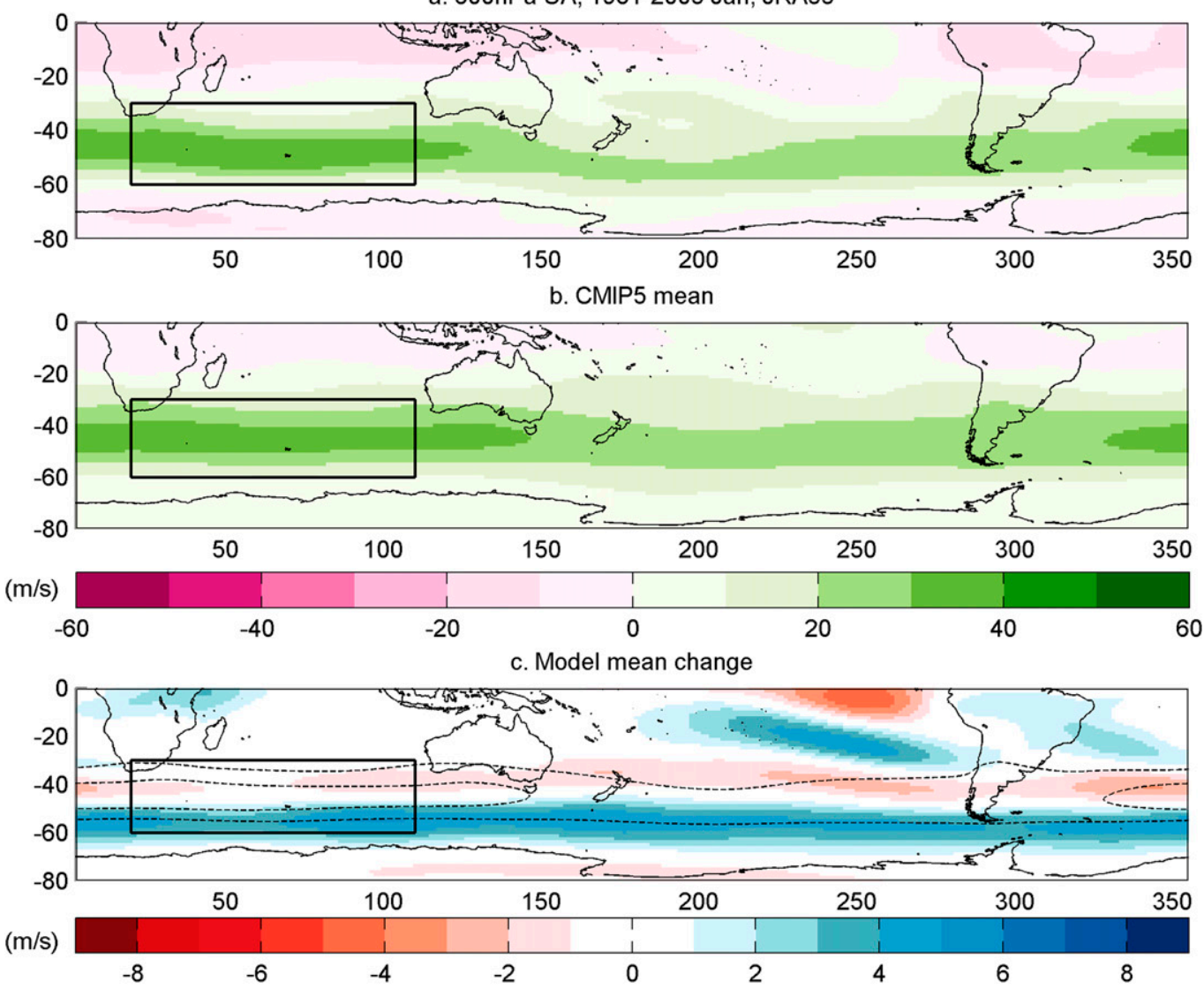

d. Jet strength

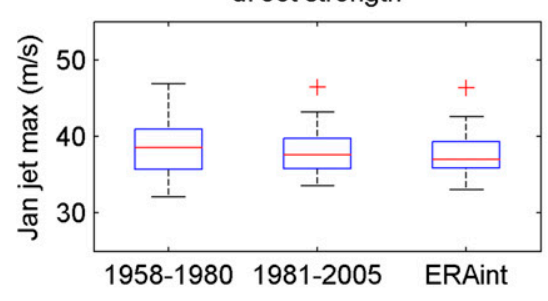

f. Jet strength bias and change
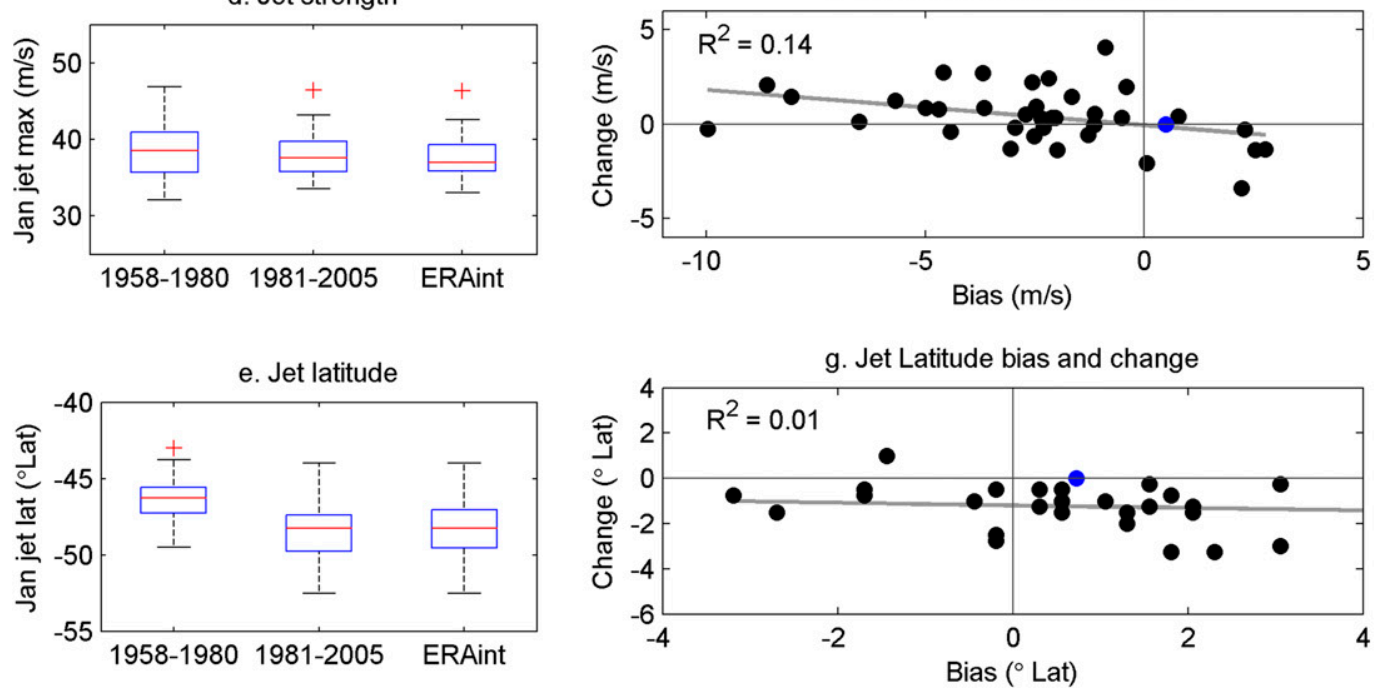

FIG. 3. As in Fig. 2, but for January.

intensification may also be underestimated. This suggests that models may underestimate the future rainfall reduction and so supports a constraint on rainfall projections drier than the models, extending to a range below the model range. Alternatively, it is possible that the recent trend in observations has a strong component of natural variability. Grose et al. (2015) identified several models that were evaluated as being unsuitable for use in projections owing to the width or longitude of the annual cycle in the STR compared to observations 
(Table 1), and these are explored in the model rejection analysis below.

\section{b. Jets}

In July we see the wintertime split in mean jet circulation with a dominant subtropical jet (STJ) at $\sim 30^{\circ} \mathrm{S}$ over Australia and a weaker polar front jet (PFJ) to the south in JRA-55 (Fig. 2a). The CMIP5 mean captures the general structure of this jet (Fig. 2b); however, some models show a poor representation of the structure. The jet is projected to weaken over most of Australia but strengthen in the south of Australia (Fig. 2c). As the jet is split over this region, this represents a weakening of the subtropical jet and a strengthening of flow in the polar front jet and also in the split region, rather than a shifting south of the subtropical jet.

In JRA-55 the jet in the July box weakened slightly and moved south between 1958-80 and 1981-2005, but these changes are small (Figs. 2d,e). The mean and interannual variation is very similar in the two reanalyses in the later period. There is a spread of bias around the reanalysis in CMIP5 models in both the strength and the latitude of this peak in the jet (Figs. $2 \mathrm{f}, \mathrm{g}$ ). The projected weakening of the jet is between 0 and $20 \mathrm{~m} \mathrm{~s}^{-1}$ in CMIP5 models, and there is a reasonably strong relationship between bias and change $\left(\mathrm{R}^{2}=0.6\right)$ where a large positive bias is associated with the greatest reduction and a large negative bias is associated with the smallest reduction in strength (Fig. 2f). This suggests that the extremes of the projected range are less plausible than the middle (around 5 to $10 \mathrm{~m} \mathrm{~s}^{-1}$ reduction). Models with a bias of more than one standard deviation from the mean $\left(3.7 \mathrm{~m} \mathrm{~s}^{-1}\right)$ in the current climate are flagged in red and rejected for the rainfall analysis as less plausible (Fig. 2; Table 1). The peak in the jet is projected to stay at approximately the same latitude in most models, with no relationship between bias and change (Fig. $2 \mathrm{~g}$ ), so no models are flagged.

In contrast to July, the January jet is not split and peaks at $\sim 50^{\circ} \mathrm{S}$ in the Indian Ocean, captured by the zonal mean across the January box (Fig. 3a). The CMIP5 model mean jet is too weak and slightly too far north compared to JRA-55 (Fig. 3b). The jet is projected to move poleward, seen as a weakening to the north of the peak and a strengthening to the south of the current peak (Fig. 3c). The jet in the January box stayed quite consistent in strength but moved south between 1958-80 and 1981-2005, with high consistency in the two reanalyses in the recent period (Figs. 3d,e). The jet is projected to stay relatively constant in strength, with no relationship between bias and change (Fig. 3f). The peak in the jet is projected to move $0^{\circ}-4^{\circ} \mathrm{S}$ poleward, again with no strong relationship between bias and change (Fig. 3g).

\section{c. Atmospheric blocking}

The wintertime split flow and center of atmospheric blocking in the mean atmospheric state in July can be seen in the 500-hPa zonal wind climatology in JRA-55 (Fig. 4a). CMIP5 shows a reduced split in the region compared to reanalysis (Fig. 4b), associated with an underestimation of the frequency and intensity of blocking events in this region.

There is large interannual variability in the frequency of blocked days at $150^{\circ} \mathrm{E}$ and numerous years with zero days (giving a median of zero in Fig. 4c). There was a slight reduction in the mean frequency but an increase in the high outliers (years with multiple days) in JRA- 55 between the two past periods, from 1.2 days for July in 1958-80 to 1.0 days for July in 1981-2005 (Fig. 4c). The frequency is slightly lower in NCEP1, at 0.8 days for July in 1981-2005. There are two peaks of roughly equal magnitude in blocking frequency to the east of Australia, and the mean longitude of the closest peak to Australia shifted slightly eastward in the past period, from $165^{\circ} \mathrm{E}$ in $1958-80$ and $175^{\circ} \mathrm{E}$ in $1981-2005$ in JRA-55, with fewer years having a peak in blocking west of $150^{\circ} \mathrm{E}$ (Fig. 4d). The mean longitude in NCEP1 in $1981-2005$ is $177^{\circ} \mathrm{E}$ (Fig. 4d).

There is a spread of bias in CMIP5 models, and this bias is generally larger than the difference between reanalyses, from a model with 3.2 days for July to a model with 0 blocked days for July in the current climate (Figs. $4 \mathrm{e}, \mathrm{f}$ ). The frequency of blocked days at $150^{\circ} \mathrm{E}$ is projected to decrease markedly (mean $72 \%$ decrease with seven models simulating no blocked days in the future climate), a decrease that is stronger than the observed decrease between the two past periods (Fig. 4e). There is a strong relationship between the current mean and the future mean $\left(R^{2}=0.69\right)$. This relationship is even stronger when expressed as the relationship between current mean and projected change consistent with other analyses in the paper $\left(R^{2}=0.93\right.$; Fig. $\left.4 \mathrm{e}\right)$. Similar to jet strength, the relationship suggests that models with the highest and the lowest projected change are less plausible than the middle of the range. Again we flag models more than one standard deviation from the mean ( 0.81 days for July) but also flag all models that simulate less than 0.5 days for July (half the observed frequency), as these are also clearly affected by bias.

Many models do not feature the distinct double peak in blocking frequency to the east of Australia found in reanalysis, and in these cases the longitude of the single major peak is detected rather than the closer of two peaks. There is a spread of bias in the CMIP5 models' longitude of the peak in blocking frequency (Fig. 4f). 

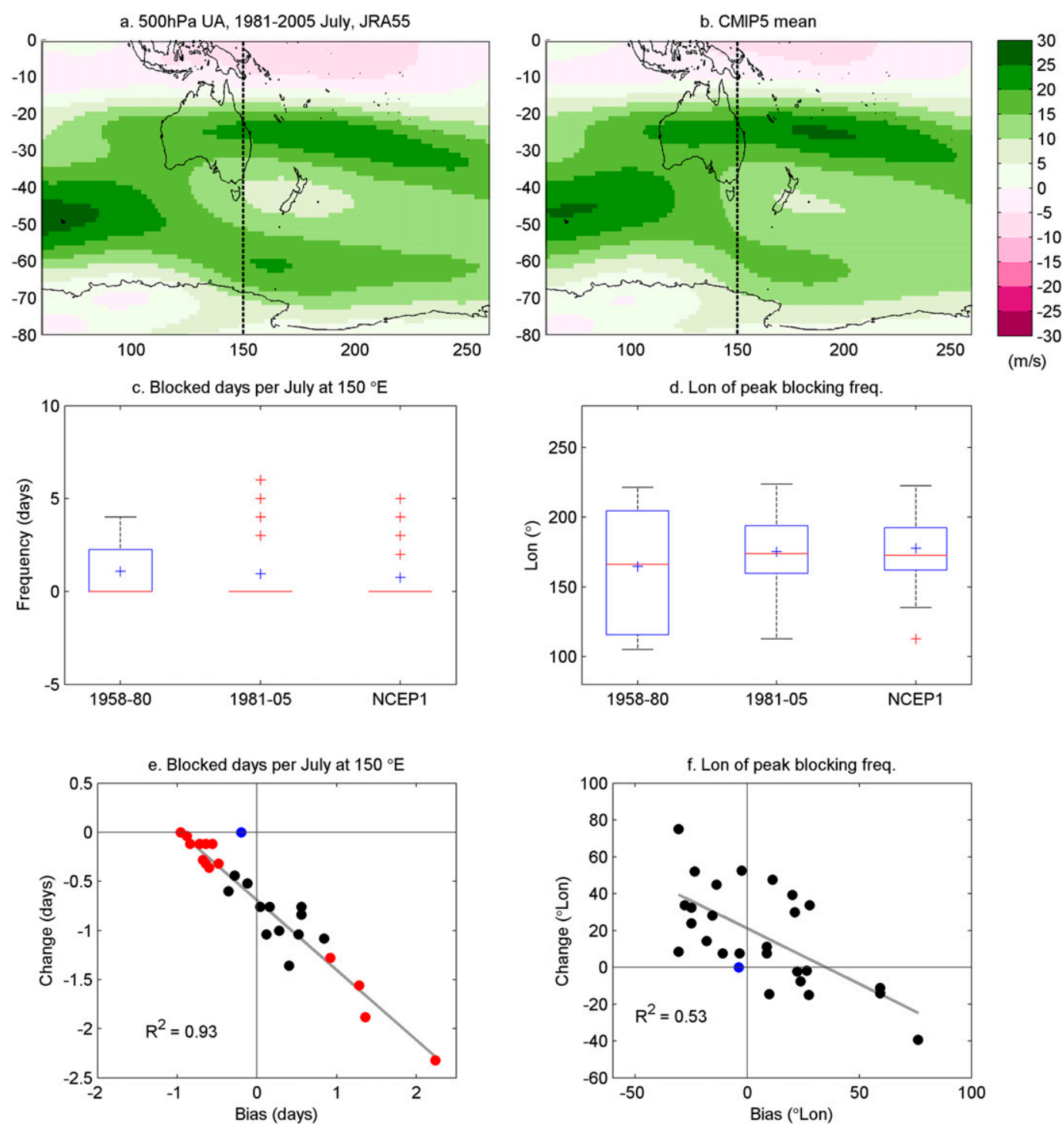

FIG. 4. Split flow and atmospheric blocking for July in reanalysis and CMIP5 models: (a) mean 500-hPa zonal wind in JRA-55 in 1981-2005, where the dashed line indicates the $150^{\circ} \mathrm{E}$ meridian; (b) mean 500-hPa zonal wind in CMIP5 model mean in 1981-2005; (c) box plot of July blocking frequency at $150^{\circ} \mathrm{E}$ in JRA-55 in 1958-80, JRA-55 in 1981-2005, and NCEP1 in 1981-2005 (blue plus symbols indicate the mean); (d) as in (c), but for longitude of peak in the frequency of blocked days (peak closer to Australia of the double peak); (e) mean frequency of blocked days for July in 26 CMIP5 models, showing bias relative to JRA-55 in 1981-2005 (1.0 days for July) plotted against projected change between 1981-2005 and 2075-99, where flagged models are red, others are black, and the blue dot shows the bias between ERA-Interim and NCEP1 on the $x$ axis; (f) mean longitude of the peak in blocking frequency in July relative to $\mathrm{NCEP} 1\left(175^{\circ} \mathrm{E}\right)$ plotted against projected change in longitude.

The peak of blocking is projected to move eastward farther into the Pacific by most models (mean of $17^{\circ} \mathrm{E}$ movement). There is a weak relationship between the bias and change in the longitude of peak blocking frequency, with the models with an eastward bias in the current climate showing a westward movement (Fig. 4f). Three models with the largest easterly bias that show this westerly change are rejected in the rainfall analysis, as this bias appears to affect the direction of change (already flagged from frequency analysis).

\section{d. Baroclinic instability and storm tracks}

Projected changes in the latitude of the Southern Hemisphere storm track show a weak but significant relationship to model bias in both CMIP3 (Kidston and Gerber 2010) and CMIP5 (Chang et al. 2012), making 
it a possible candidate for emergent constraints on regional climate projections. However, a simple analysis of storm tracks did not suggest a constraint based on the relationship between bias and change (Schaller et al. 2011). Here we examine two dynamically based measures of storms and focus on a subregion of the Southern Hemisphere relevant to Australian rainfall. We examine baroclinic instability as a measure of storm origin and temperature variance at $500 \mathrm{hPa}$ as a measure of the track itself over the Australian box in July and the Indian Ocean box in January. Changes in each sector are already noted to be different from the hemispheric mean in some seasons, particularly in the Northern Hemisphere but with some subtle changes in the Southern Hemisphere (e.g., larger changes south of Australia than in other sectors in the cool season; Simpson et al. 2014).

Baroclinic instability measured by the Phillips instability criterion in July is highest in the STJ region over Australia, with a local minimum in the southern Tasman Sea (Fig. 5a). The CMIP5 mean reproduces this structure, but with some difference in the latitude of the peak and the location of the minimum (Fig. 5b). The multimodel mean shows a projected weakening of baroclinic instability in the peak region over Australia but a strengthening south of Australia (Fig. 5c). Interestingly, the pattern of change is different over South America (Fig. 5c). The peak baroclinic instability in the box moved poleward and strengthened slightly between the two periods, but these changes are slight and not statistically significant (Figs. 5d,e). Results are similar in the two reanalyses for the recent period. CMIP5 models show a spread in bias around reanalysis, but with more models showing an equatorward rather than a poleward bias (Figs. 5f,g). Models do not agree on the sign of projected change in either strength or latitude, and there is no significant relationship between bias and change in both cases (Figs. 5f,g), similar to that found in CMIP3 (Frederiksen et al. 2011). Therefore, no models are flagged as less plausible in the rainfall analysis.

In January the baroclinic instability is highest in the southern Indian Ocean, and the peak extends south of Australia (Fig. 6a). The pattern is well reproduced in the CMIP5 mean but with a slight weak bias in places and a different shape south of Australia (Fig. 6b). The multimodel mean shows baroclinic instability is projected to weaken to the north and strengthen to the south of the peak fairly consistently around the hemisphere (Fig. 6c). The peak baroclinic instability in the box weakened and moved poleward between the two past periods, with consistent results in the later period in the two reanalyses (Figs. 6d,e). Similar to July, among models there is bias and projected change of both signs for both strength and latitude, with no strong relationships in the intermodel spread (Figs. 6f,g). Therefore, no models are flagged for rejection here either.
The storm track in July is split over Australia, similar to the jets but with a greater activity on the PFJ rather than the STJ (Fig. 7a). This means that the STJ analysis box is used to quantify the secondary peak relevant to Australian rainfall; however, we also examined another box over the PFJ region at $40-70^{\circ} \mathrm{S}$, also marked in Fig. 7a. The CMIP5 mean storm track is not as distinctly split into two defined branches as the reanalysis (Fig. 7b). The storm track is projected to weaken slightly over the STJ region but strengthen over the PFJ region (Fig. 7c).

The secondary track in the STJ region strengthened slightly between the two past periods (Fig. 7d) and stayed relatively steady in latitude (Fig. 7e), with similar results in the recent period in each reanalysis. There is a spread of model bias in strength, but most models have a northerly bias (Figs. 7f,g). Models do not agree on the direction of projected change and there is no relationship across the spread in models in terms of bias and change for either metric in the STJ region (Figs. 7f,g).

The storm track on the PFJ branch strengthened but did not change markedly in latitude between the two periods in the reanalysis (Figs. 8a,b). This branch is projected to strengthen further, but with no relationship between current bias and projected change (Fig. 8c). However, the latitude bias has a relationship to the latitude shift $\left(\mathrm{R}^{2}=\right.$ 0.68 ; Fig. 8d). Models with the greatest equatorward bias show a small shift or poleward movement, and models with a lower bias show a slight equatorward shift (Fig. 8d). This is possibly related to the reduction in blocking and closing of the split jet structure, causing the PFJ to become more zonal. Models with a bias of more than one standard deviation from the mean (5.88) are flagged for rejection in the rainfall analysis (Fig. 8d). This rejection includes all models with a northerly bias sufficient to project a southerly movement in the PFJ region.

In January, the storm track is too weak and slightly too far north in the CMIP5 mean compared to reanalysis (Figs. 9a,b). The storm track is projected to weaken to the north and strengthen to the south of the peak, consistent with a poleward movement (Fig. 9c). The storm track in the January box strengthened (Fig. 9d) and moved poleward (Fig. 9e) in the recent past, in line with the hemispheric mean. Models do not agree on the sign of projected change in the strength of the peak of the storm track in the box, with no relationship between bias and change (Fig. 9f). Models agree on a southerly shift in the latitude of the peak in the box, but with no relationship between bias and change (Fig. 9g).

\section{e. Rainfall projections-Model rejection}

Given that selecting some models for rejection based on circulation features reduces the range of projected change for those circulation features, we test whether 
a. PC Instability Criterion (PC), JRA55


d. PC strength

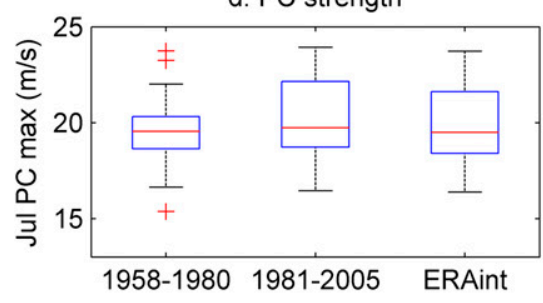

f. PC strength bias and change
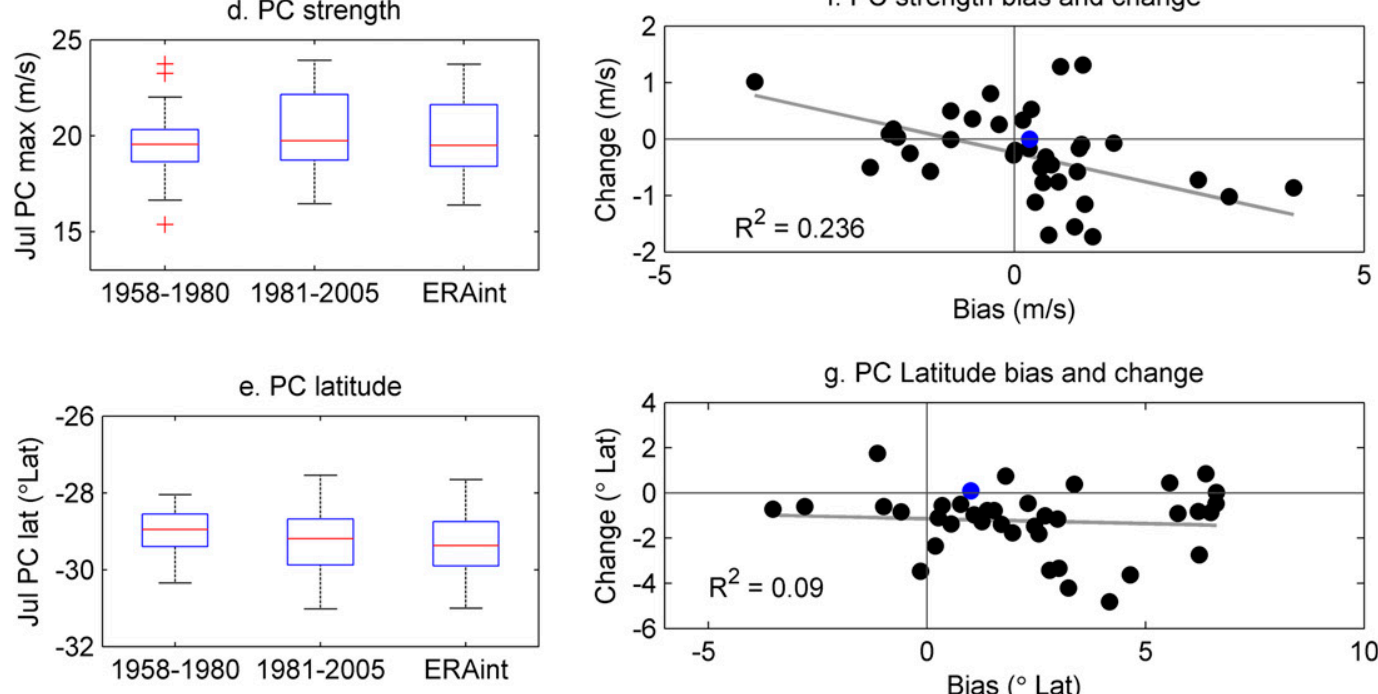

g. PC Latitude bias and change

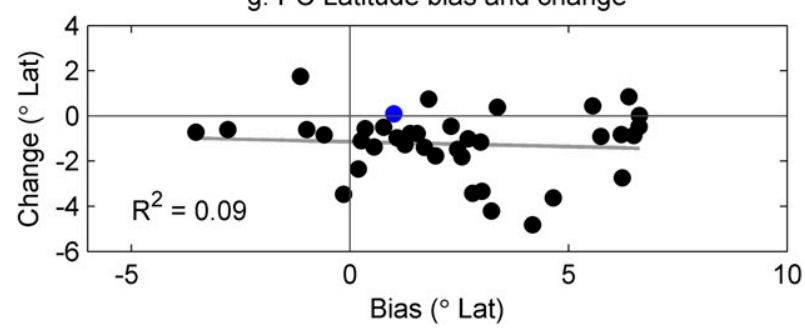

FIG. 5. Baroclinic instability measured by the Phillips instability criterion (PC) in July in reanalysis and CMIP5 models: (a) mean in JRA-55 in 1981-2005; (b) mean in 1981-2005 in the CMIP5 mean; (c) multimodel change from 1981-2005 to 2075-99, where dashed lines are the 10 and $15 \mathrm{~m} \mathrm{~s}^{-1}$ contours in the model mean in the current climate and results north of $20^{\circ} \mathrm{S}$ in (a)-(c) are masked; (d) box plot of July PC strength in zonal mean of box in each year in JRA-55 in 1958-80, JRA-55 in 1981-2005, and ERA-Interim in 1981-2005; (e) as in (d), but for latitude; (f) results from 37 CMIP5 models in the zonal mean of the box in the climatology, bias in 1981-2005, and projected change to 2075-99, where the blue dot shows the bias between ERA-Interim and JRA-55 on the $x$ axis; (g) as in (f), but for latitude. 
a. Jan Phillips Instability Criterion (PC), JRA55
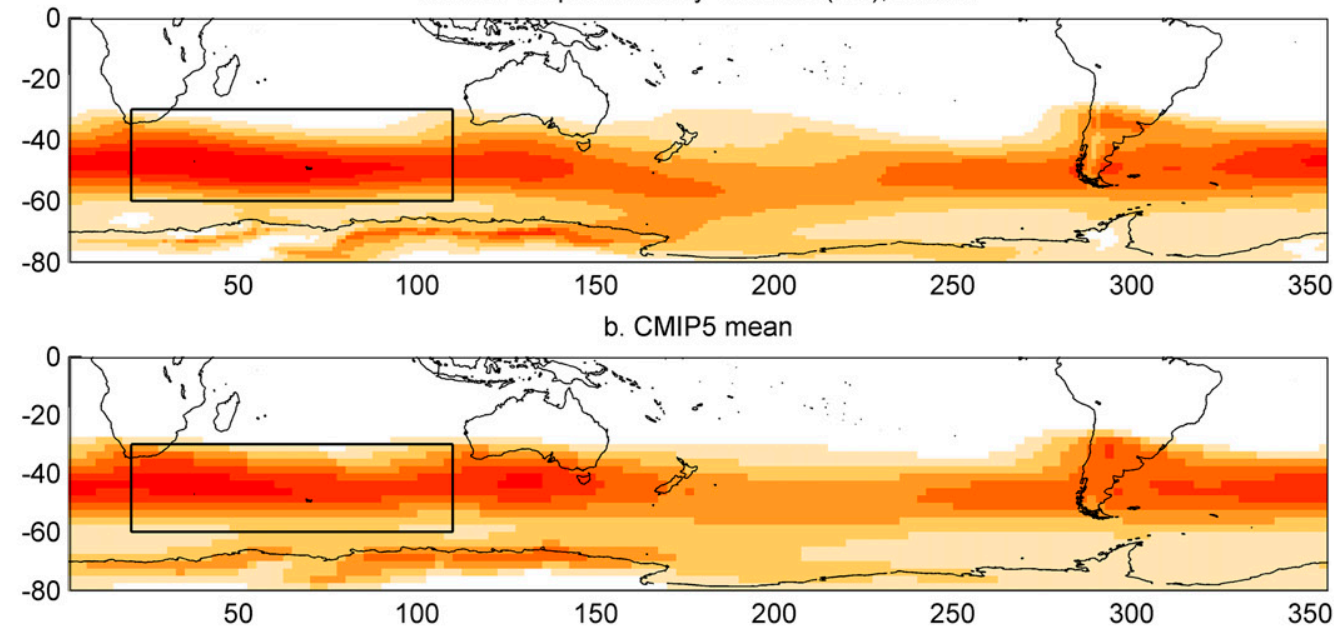

$(\mathrm{m} / \mathrm{s})$

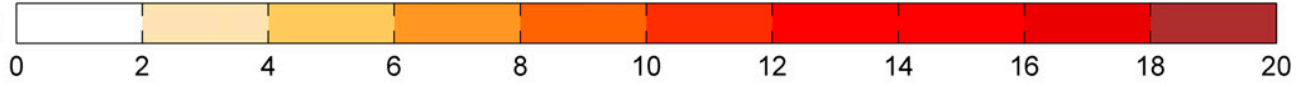

c. Model mean change

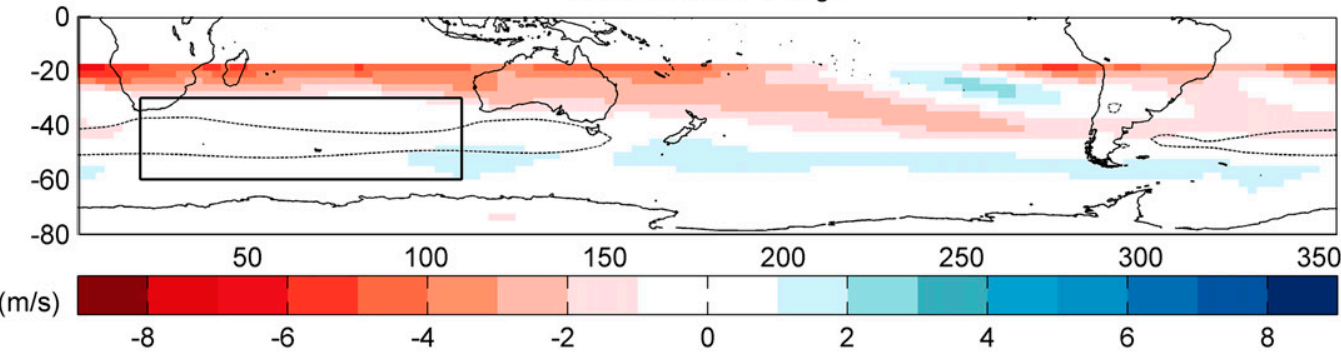

d. PC strength

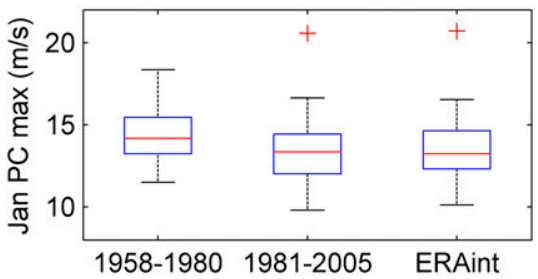

f. PC strength bias and change

e. PC latitude
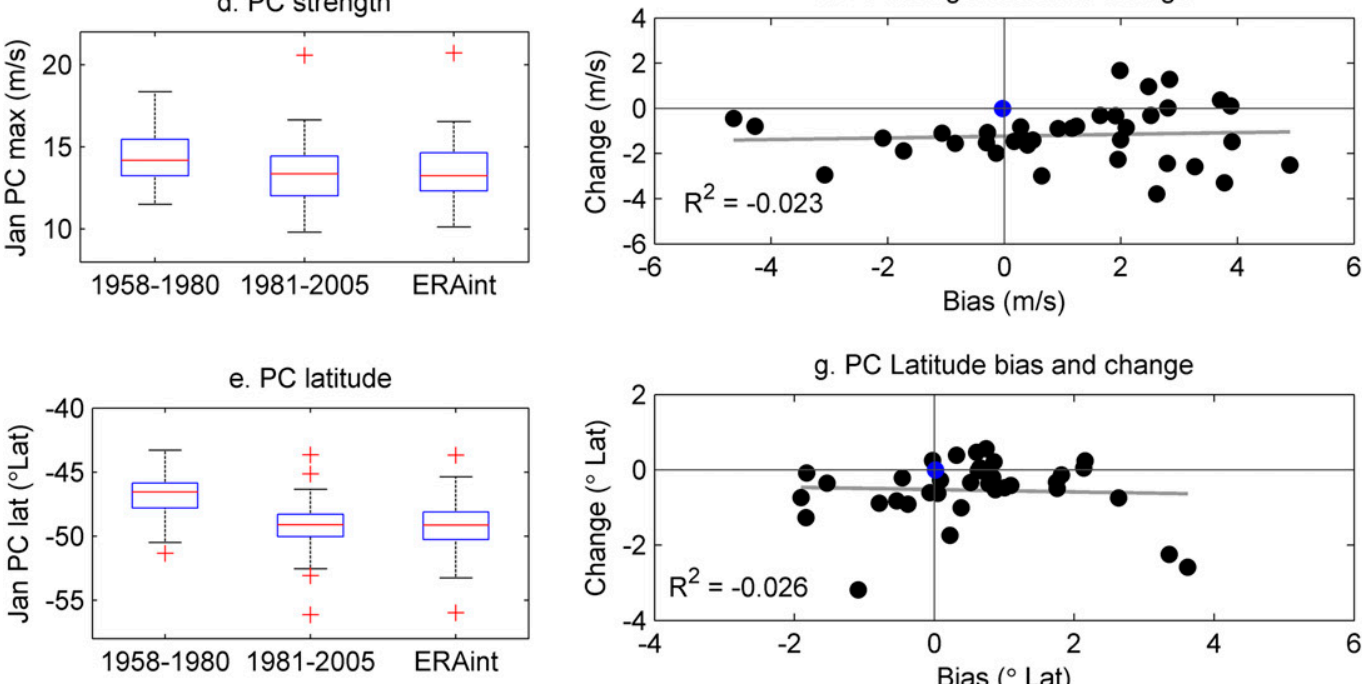

g. PC Latitude bias and change

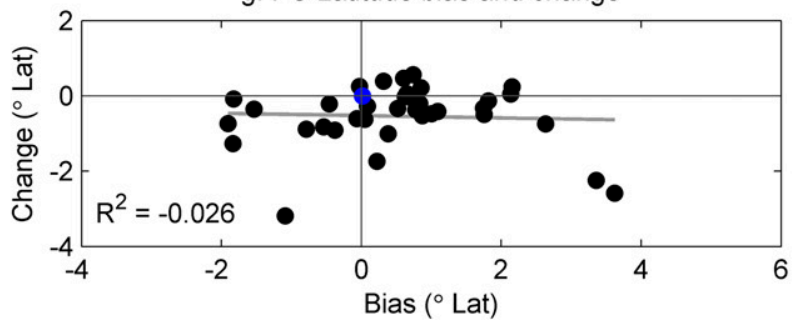

FIG. 6. As in Fig. 5, but for January.

this leads to a reduction in projected change in rainfall for southern Australia as well. Here we examine the rainfall projection for the southern Australian region as defined in Whetton et al. (2015) (indicated by the red boundary in Fig. 10) for RCP8.5 for 1986-2005 to 2080-99. Of the
40 models in the original ensemble, 27 models were included in all tests. We use only the analyses with notable relationships between bias and change to identify "passed" and "failed" models. We labeled 15 models as "passed" as they were outliers in only one relationship 
a. $500 \mathrm{hPa}$ temperature variance, 1976-2005 Jul, JRA55
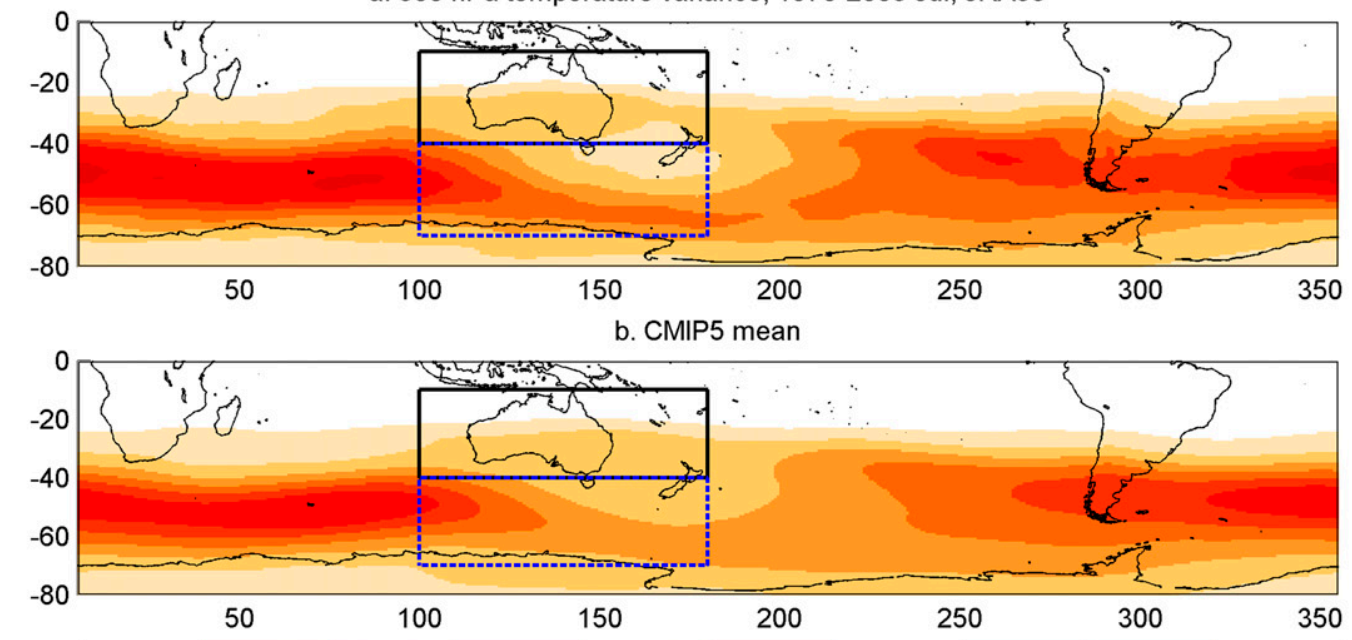

var

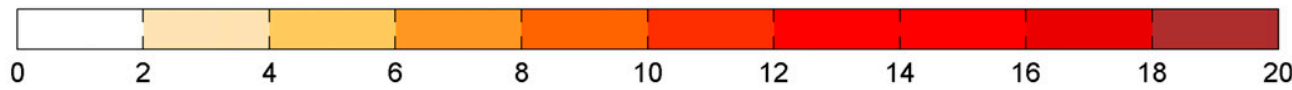

c. Model mean change

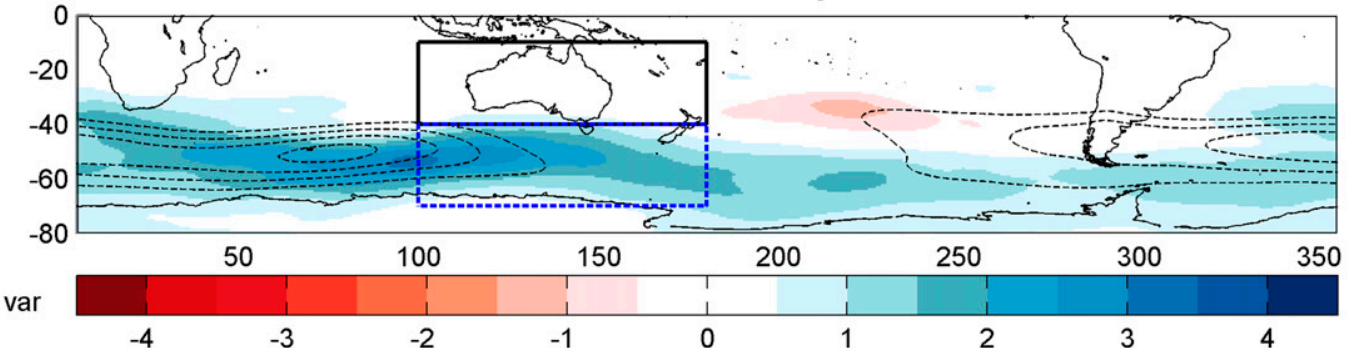

d. Storm track strength



f. Storm track strength

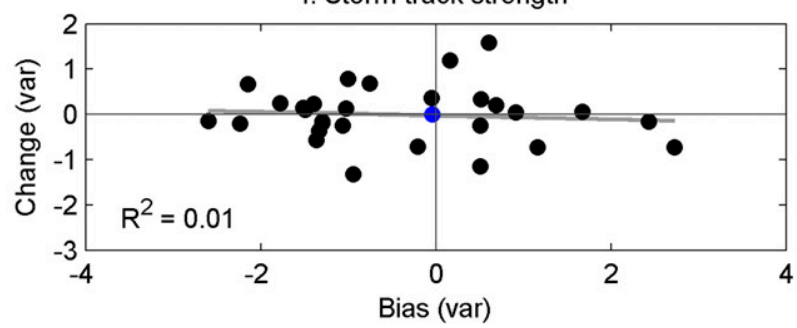

e. Storm track latitude
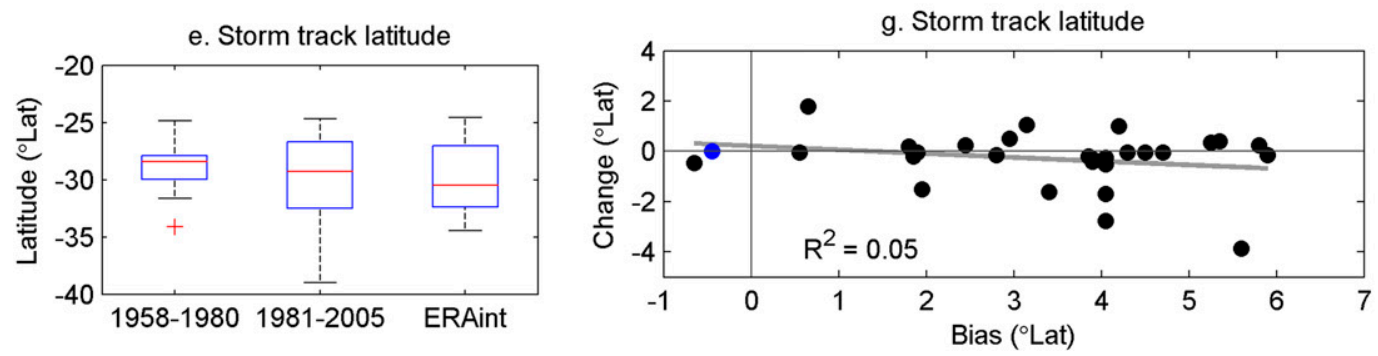

FIG. 7. Storm tracks measured as variance in 500-hPa temperature in the 2-10-day band in July in reanalysis and CMIP5 models: (a) mean in JRA-55 in 1981-2005; (b) CMIP5 mean in 1981-2005 showing box used for analysis in this figure (black line) and for the PFJ region in Fig. 8 (blue dashed line); (c) multimodel mean change between 1981-2005 and 2075-99, where dashed lines are the 1.5, 2, 2.5, and $3 \mathrm{~m} \mathrm{~s}^{-1}$ contours in the CMIP5 mean in the current climate; (d) mean peak value in zonal mean in STJ box in (from left to right) JRA-55 in 1958-80, JRA-55 in 1981-2005, and ERA-Interim in 1981-2005; (e) as in (d), but for latitude of the peak; (f) results from 29 CMIP5 models of storm track in the PFJ box in the July climatology, bias in 1981-2005 compared to JRA-55, and projected change to 2075-99, where flagged models are red, others are black, and the blue dot shows the bias between ERA-Interim and JRA-55 on the $x$ axis; (g) as in (f), but for latitude. 

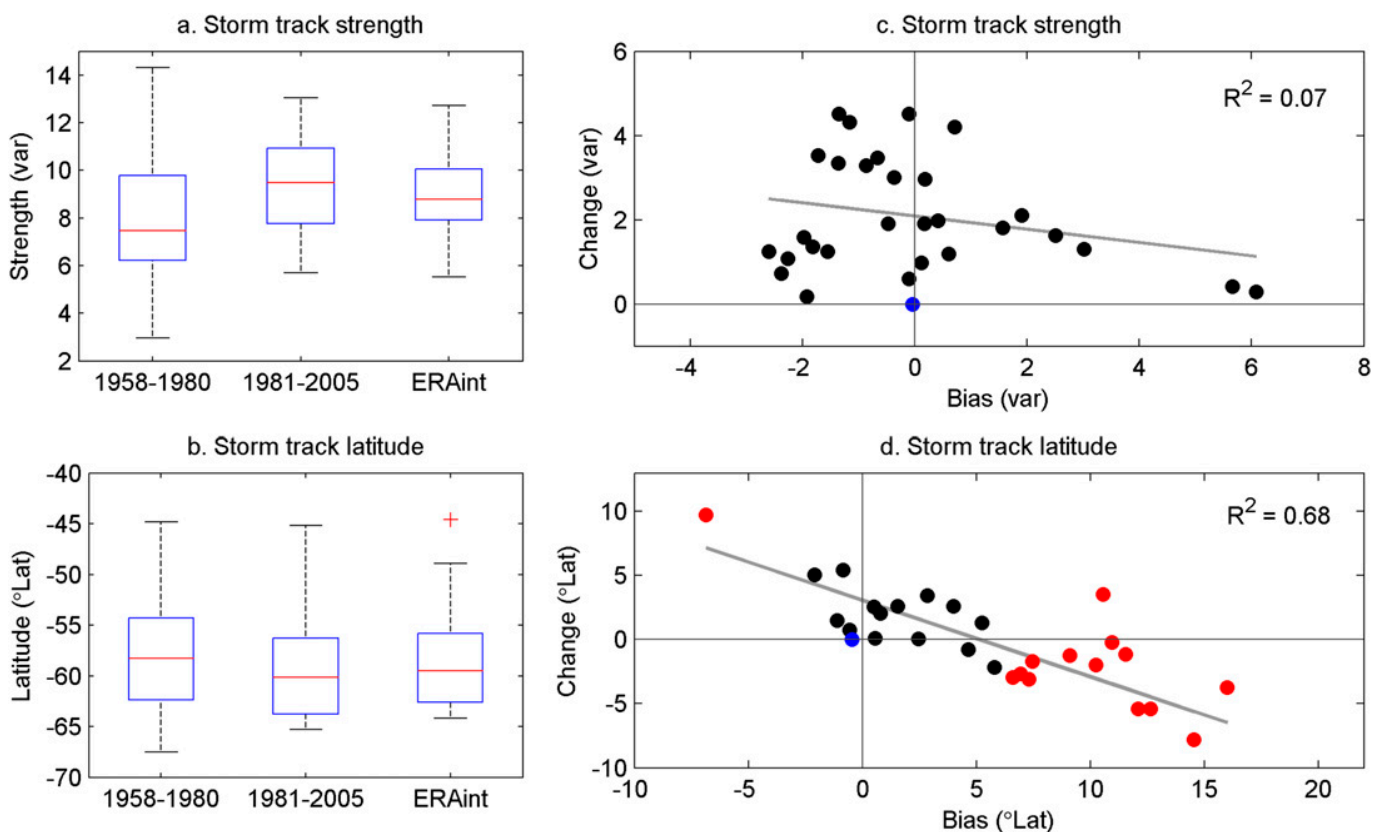

FIG. 8. As in Figs. 7d-g, but for the polar front jet box (blue dashed line in Fig. 7).

or none at all. We labeled 14 models as "failed" as they were indicated as outliers in two or more relationships. The GISS-E2-R and CSIRO Mk3.6.0 models were not tested for all tests but failed two tests, so they are included in the failed group although not appearing in the tested list (Table 1). Flagged models could be rejected for only July rainfall, as this is where all relationships were found. However, we also apply the same analysis to January rainfall, as there is a case to reject models with large biases in one season for use in any season.

In July the projected rainfall change in the ensemble of 40 models (median of $-17 \%$ ) is similar to the 28 evaluated for all circulation features (median of $-19 \%$ ), and the $10 \%-90 \%$ range is also similar (Fig. 10a). The median and $90 \%$ confidence interval are more negative in the passed group (median of $-24 \%$ ) than in the failed models (median of $-14 \%$ ). The two samples are significantly different (Student's $t$ test; $p=0.04$ ). Notably, the upper range of change is reduced in the accepted models, with an upper projection of $-5 \%$ in this subset (compared to $+5 \%$ in the rejected set). The spatial distribution in the multimodel mean change is similar in the whole ensemble and the subsets despite this difference in projected median and range (Figs. 10b-d), except perhaps with a more spatial uniform pattern of change in the failed models (e.g., lower rainfall decrease in the southwest).

Figure 11 shows the results if the models flagged from the analysis of July circulation are used in rejection analysis for January rainfall. Here the tested group gives a similar range of projected change to the full ensemble. The ensemble mean is close to zero in all model groups, but the range of change is different. The passed models show a narrower range of projected change, with fewer outliers than the whole ensemble. The passed ensemble shows no projected changes larger than $25 \%$ in either direction (Fig. 11a). Again the spatial distribution in each model subset is not particularly different from the whole ensemble (Figs. 11b-d), but here the median projection is also similar in the different model subsets (Fig. 11a).

\section{Discussion}

Here we examined the projected change to the main circulation features relevant to Australian rainfall and the effect on rainfall projections in southern Australia. In some cases there is high model agreement in the projected change in the strength or position of key circulation features in our selected CMIP5 models. In some other cases the relationship between the current bias and projected change between models in these features suggest certain constraints on the range of projected change. This leads to suggested constraints not only in the atmospheric circulation features but also on the corresponding rainfall projection for southern Australia in July and January for RCP8.5 by the end of the century.

In July, the analysis of past trends in the subtropical ridge taken from Grose et al. (2015) suggests that the 
a. $500 \mathrm{hPa}$ temperature variance, 1981-2005 Jan, JRA55
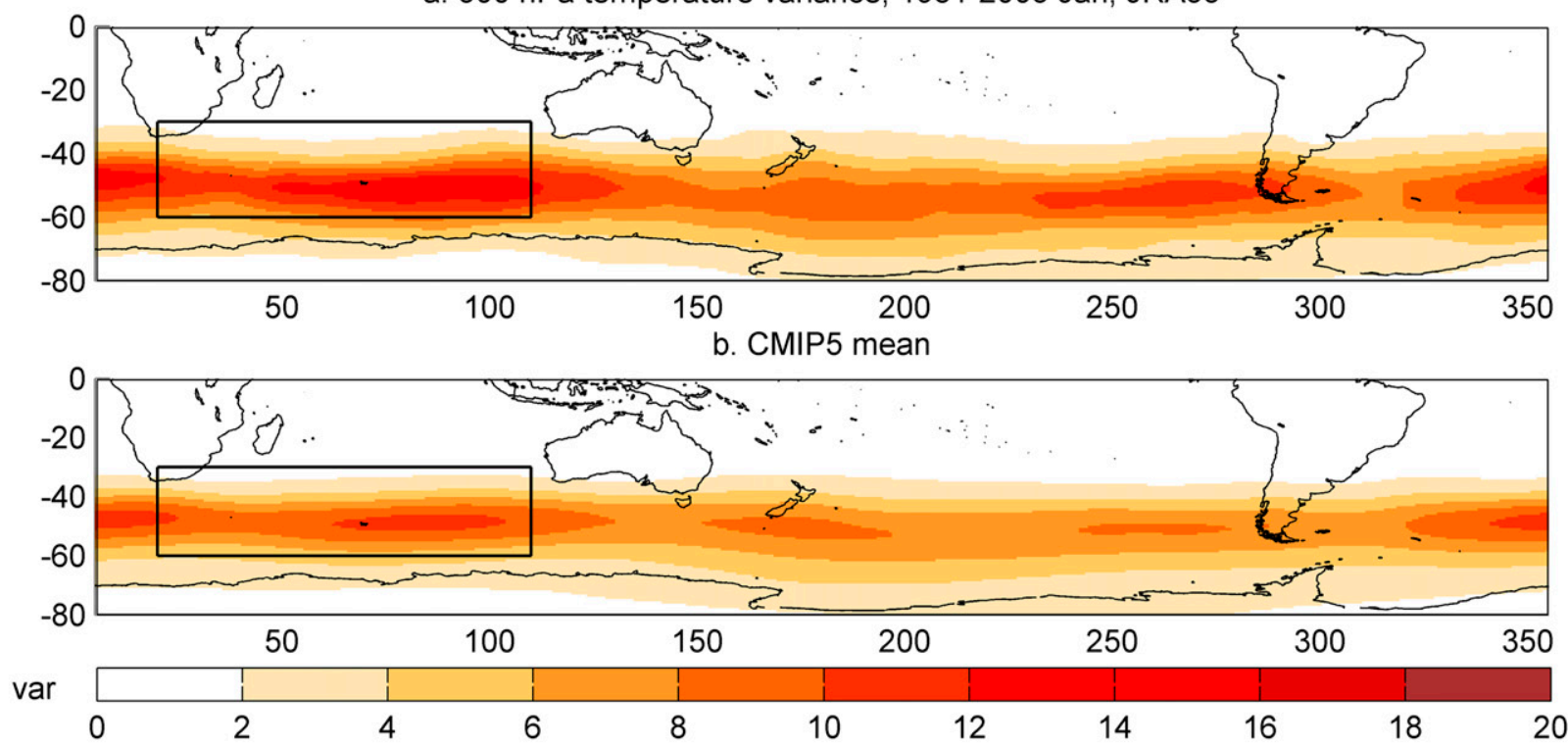

c. Model mean change

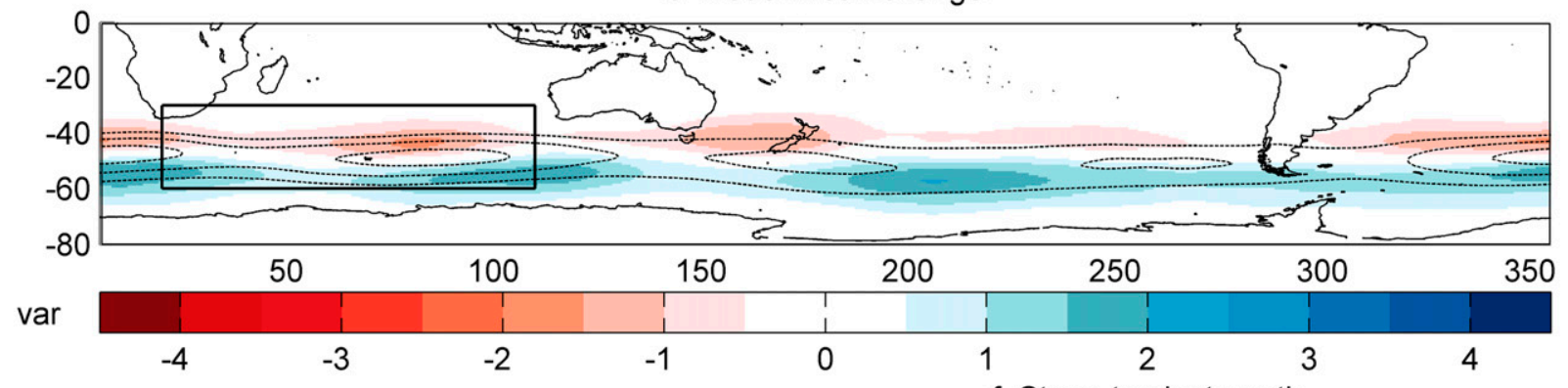

d. Storm track strength

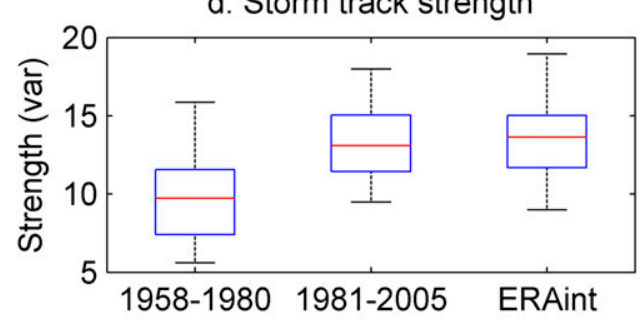

f. Storm track strength

e. Storm track latitude
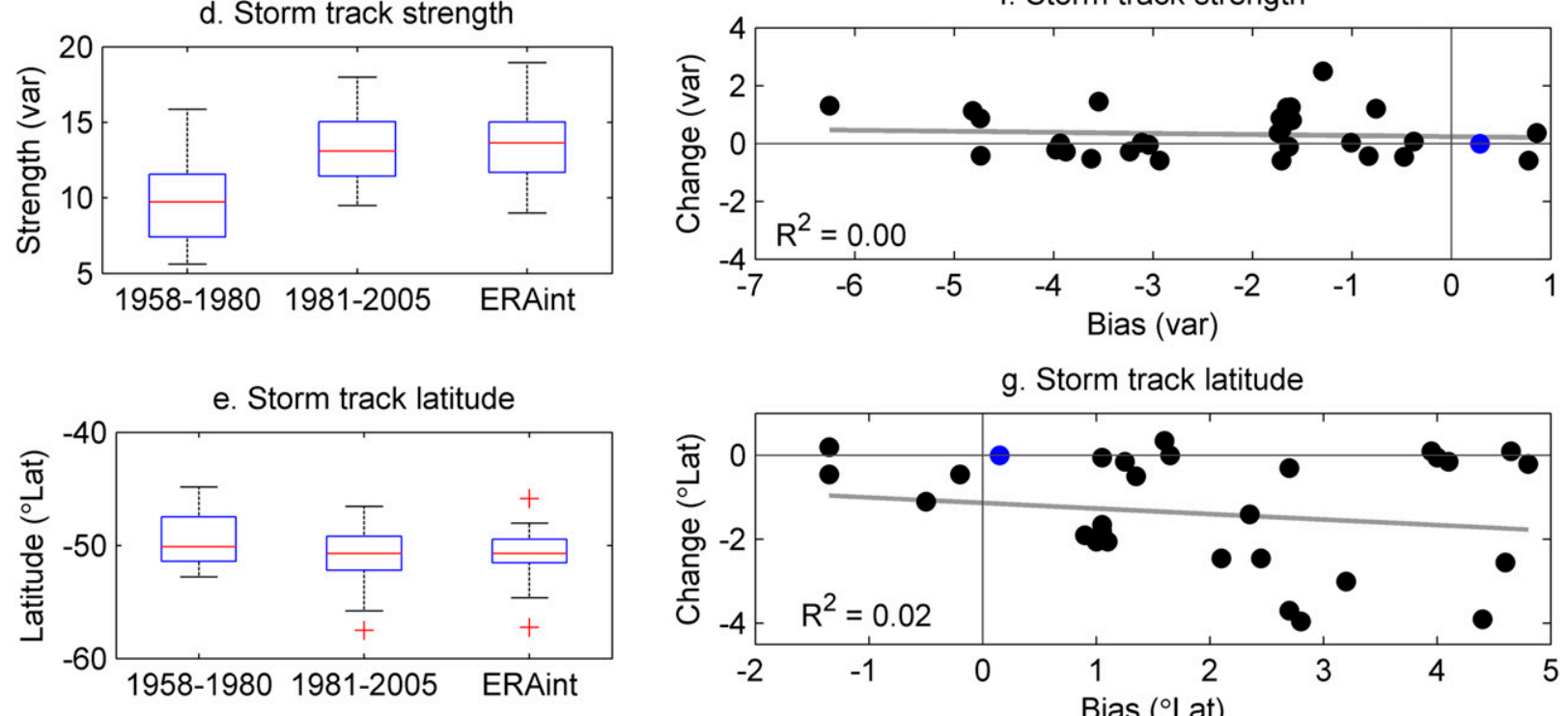

g. Storm track latitude

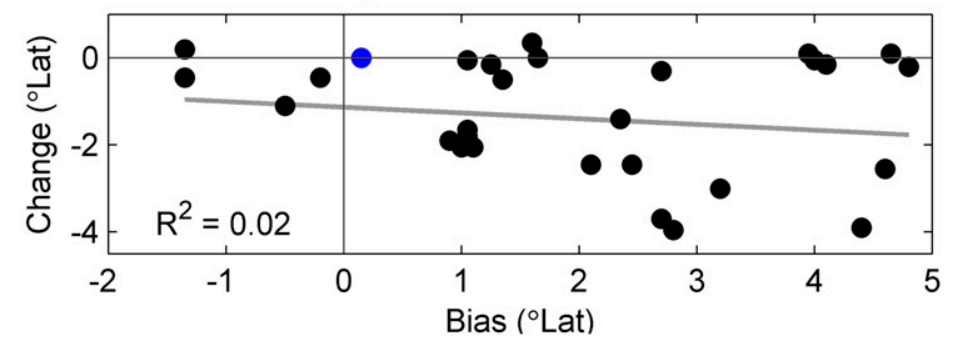

FIG. 9. As in Fig. 7, but for January. 

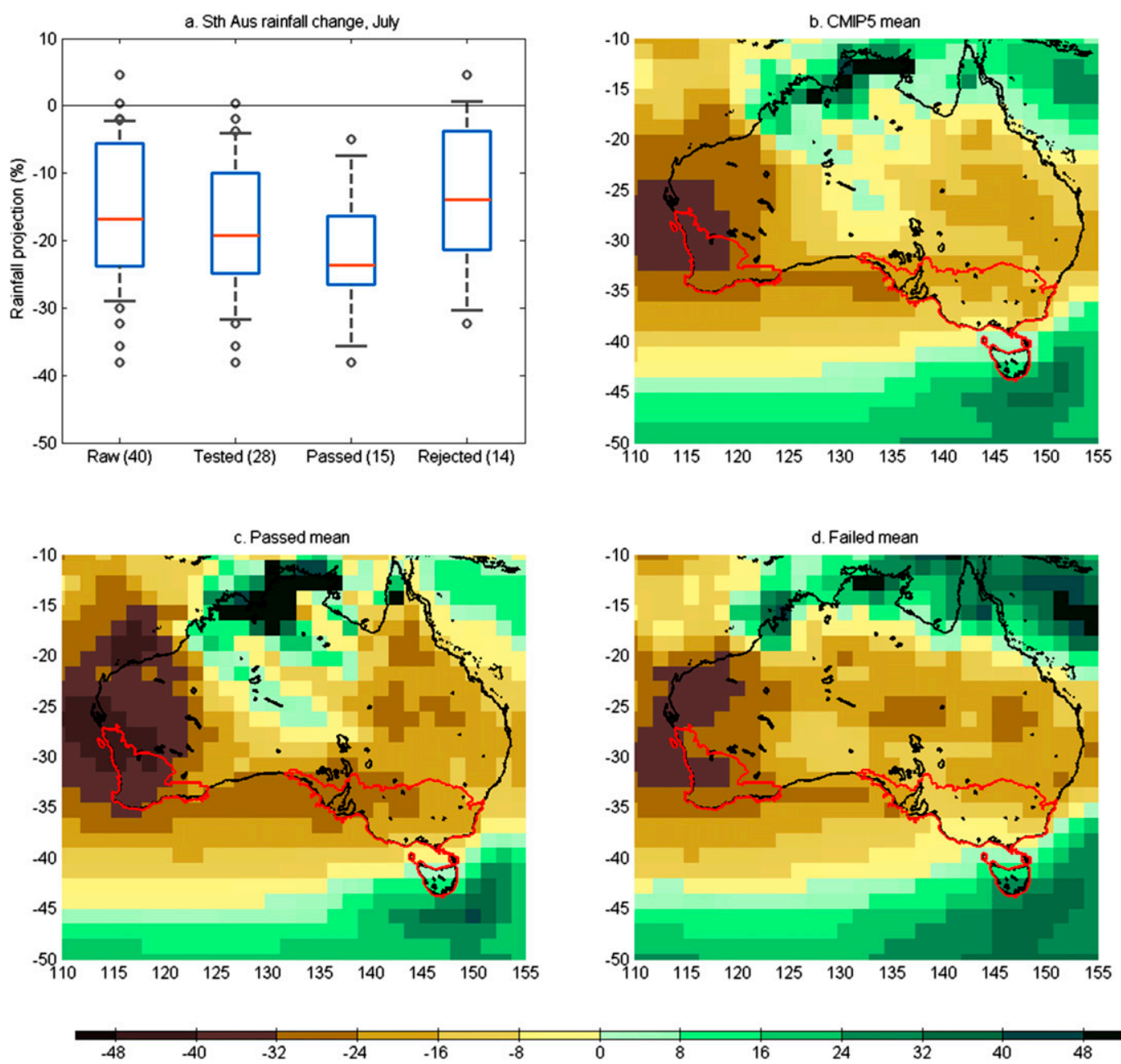

FIG. 10. Rainfall projections (\%) for southern Australia in July for 1986-2005 to 2080-99 under RCP8.5 from 40 CMIP5 models, 28 models evaluated for all circulation features (tested), 15 models that passed tests or all except one (passed), and 14 models failing two or more tests (rejected): (a) box plots where whiskers are $10 \%-90 \%$ and outliers shown as circles and (b)-(d) multimodel means of groups (red line shows the outline of the southern Australia region used in the bar plot).

intensification of the ridge to greenhouse forcing in models may not be strong enough. This suggests the STR could intensify more, with a correspondingly greater reduction in rainfall, than any model simulates. Hence, a rainfall projection of increase or little change is not as likely as a more marked decrease.

The subtropical jet is projected to weaken, and the relationship between models in terms of bias and projected change suggests that the middle of the projected range $\left(\sim 10 \mathrm{~m} \mathrm{~s}^{-1}\right)$ is more likely than either little change or a reduction of $\sim 15 \mathrm{~m} \mathrm{~s}^{-1}$. The frequency of atmospheric blocking is projected to decrease by $\sim 70 \%$ at $150^{\circ} \mathrm{E}$, and the peak in blocking frequency is projected to move farther east into the Pacific by approximately $20^{\circ}$ longitude. The relationship between model bias and projected change suggests that models with a large bias are unduly affected by this bias in terms of the absolute number of blocked days and in the longitude of peak blocking. Specifically, the results suggest that reductions of less than 0.5 days in July or more than 1.5 days in July are not physically plausible, and neither is a westerly movement of the peak.

There is low consensus on the projected sign of change in either the strength or latitude of baroclinic instability in this sector, and there is no relationship between bias and change to suggest a constraint. The storm track is much stronger on the polar front jet branch than the subtropical jet branch in July, and the polar front jet is projected to strengthen and move farther north, consistent with a reduction in blocking. The relationship between bias and change suggests a southerly movement of the strong PFJ branch is less likely than a northerly 

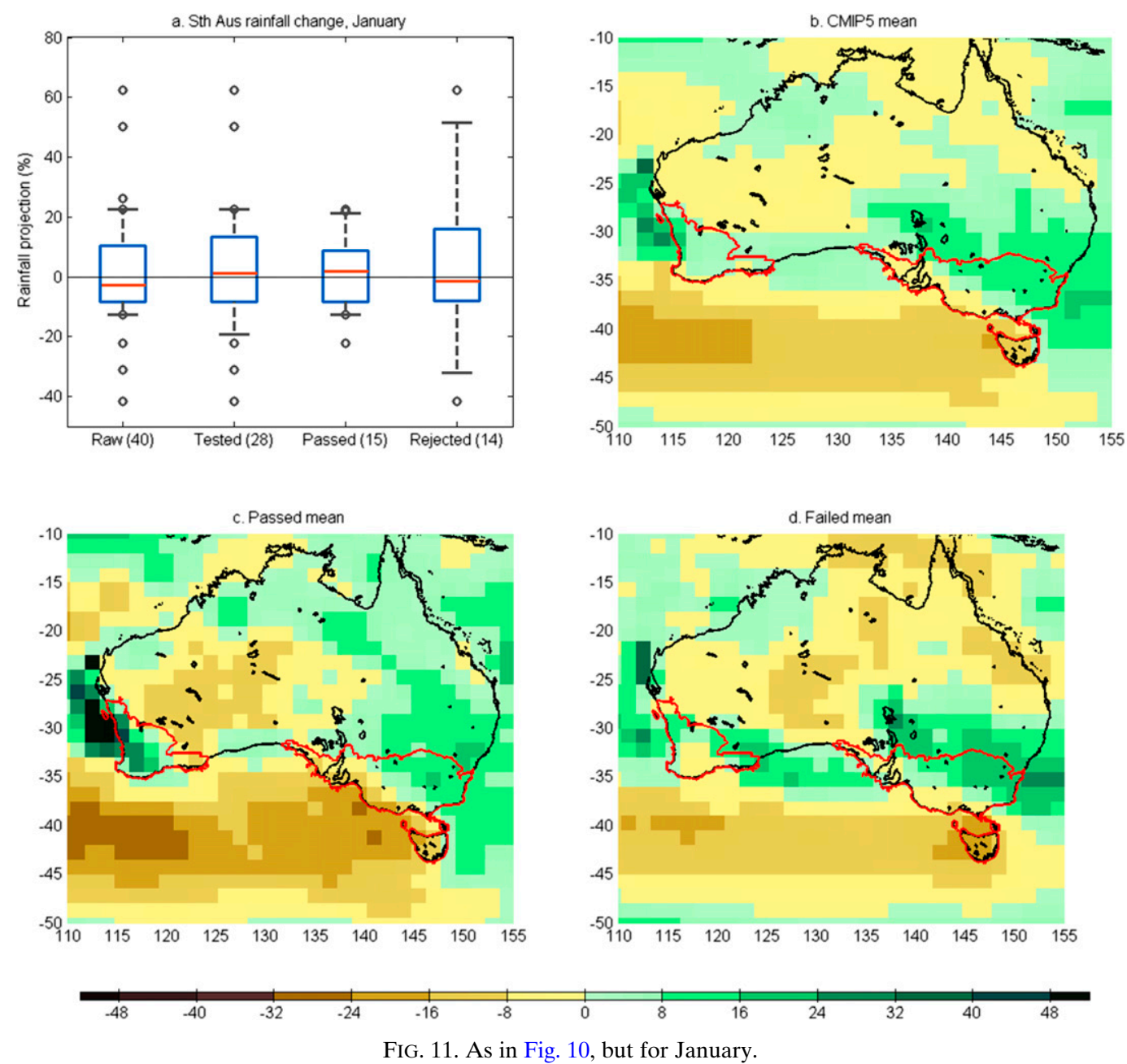

movement, in contrast to the hemispheric mean. Projected change in the weaker STJ branch of the storm track is less clear.

In January, the circulation is more zonally symmetric and blocking analysis is not included. In the peak region in the Indian Ocean sector upstream of Australia, the jet, baroclinic instability, and storm track are all projected to move south. This change is associated with a rainfall reduction to the south of Australia, but other influences also affect the rainfall projection for southern Australia. In January there were no strong relationships between bias and projected change that suggested a constraint, but we examine the rejection of models from the July analysis here as well, assuming that unphysical relationships for a model in one season also raise doubts for the projection in other seasons.

To examine rainfall change in southern Australia, we rejected models that have particular biases in circulation features where those biases appear to have an unreasonable effect on the projected change in those features. This relies on demonstrating a relationship between bias and projected change to determine thresholds for rejection.

Using these relationships to reject models, the rainfall projection for southern Australia in the accepted models shows two notable differences compared to the full ensemble. In July the wetter end of the projected range of change is not present in the reduced model ensemble. This suggests that a rainfall increase is less likely than the original ensemble suggests, and a reduction of at least $-5 \%$ is more likely than indicated in the original ensemble. The dry end of the projected range remains, and the limit to potential rainfall reduction potentially beyond the model range cannot be examined from these results. However, the subtropical ridge results suggest that a greater reduction than the model range is possible as the models likely underestimate the magnitude of future intensification in STR. If the models with poor simulation of circulation features in July are also rejected for January analysis, the extreme outliers of the January rainfall projection are removed ( $>25 \%$ increase or decrease). 
It is clear that CMIP5 models do not all have an acceptable simulation of all circulation features relevant to Australian rainfall climate and that some are candidates for rejection in producing rainfall projections on this basis. Focusing on features that show a relationship between bias and projected change gives a more reliable basis for rejecting or weighting models than a more arbitrary threshold of bias in the feature. It is also more reliable than a weighting based on the simulation of rainfall itself, which may be subject to compensating errors. However, the thresholds are still somewhat subjective; here we used one standard deviation, with an additional threshold for blocked days of 0.5 days for July from expert judgment. Future work could consider the relationship between circulation features and rainfall to produce constraints, so avoid the use of thresholds.

Here we used a simple approach based on rejection based on several key features, and this suggests a slight but potentially valuable rainfall constraint on projections. Treating a rainfall increase in July and a rainfall change of more than $\pm 25 \%$ in January as very unlikely allows users of climate projections to narrow the cases they consider when producing impact assessments. More sophisticated analysis of the relationship between multiple features or more complex systems of model weightings may reveal further useful constraints.

\section{Conclusions}

Atmospheric circulation features of the Southern Hemisphere are key influences on rainfall variability and change in southern Australia. The intermodel spread in CMIP5 in terms of bias in the current climate and projected change in these features can be used to identify potential constraints on projected climate change this century. This approach suggests four constraints: the July subtropical jet over Australia will weaken in the midrange of CMIP5 projections, the storm track within the PFJ in July will move northward slightly, blocking frequency will reduce in July, and the longitude of the peak in blocking frequency will move farther east into the Pacific Ocean. By excluding the models with biases that adversely affect their projection in these four aspects, we find notable constraints on rainfall projections in both July and January. Increase or little change in rainfall in July is rejected (minimum projection of $-5 \%$ ) and change of more than $25 \%$ or less than $-25 \%$ in January is rejected. Further circulation-based analysis is a basis for improving and constraining rainfall change projections elsewhere in Australia and other locations.

Acknowledgments. We wish to thank Penny Whetton and Josephine Brown for helpful discussion and comments.
We acknowledge the World Climate Research Programme's Working Group on Coupled Modelling, which is responsible for CMIP, and we thank the climate modeling groups for producing and making available their model output. For CMIP the U.S. Department of Energy's Program for Climate Model Diagnosis and Intercomparison provides coordinating support and led development of software infrastructure in partnership with the Global Organization for Earth System Science Portals. This work has been undertaken as part of the Australian Climate Change Science Program, funded jointly by the Department of the Environment, the Bureau of Meteorology, and CSIRO.

\section{REFERENCES}

Chang, E. K. M., Y. Guo, and X. Xia, 2012: CMIP5 multimodel ensemble projection of storm track change under global warming. J. Geophys. Res., 117, D23118, doi:10.1029/ 2012JD018578.

Dee, D. P., and Coauthors, 2011: The ERA-Interim reanalysis: Configuration and performance of the data assimilation system. Quart. J. Roy. Meteor. Soc., 137, 553-597, doi:10.1002/ qj. 828.

Drosdowsky, W., 2005: The latitude of the subtropical ridge over eastern Australia: The $L$ index revisited. Int. J. Climatol., 25, 1291-1299, doi:10.1002/joc.1196.

Flato, G., and Coauthors, 2013: Evaluation of climate models. Climate Change 2013: The Physical Science Basis, T. F. Stocker et al., Eds., Cambridge University Press, 741-866. [Available online at http://www.ipcc.ch/pdf/assessment-report/ar5/wg1/ WG1AR5_Chapter09_FINAL.pdf.]

Frederiksen, C. S., S. L. Osbrough, J. S. Frederiksen, and J. M. Sisson, 2011: Changes and projections in Australian winter rainfall and circulation: Anthropogenic forcing and internal variability. Int. J. Climate Change, 2, 143-162, doi:10.18848/ 1835-7156/CGP/v02i03/37071.

Frederiksen, J. S., and P. J. Webster, 1988: Alternative theories of atmospheric teleconnections and low-frequency fluctuations. Rev. Geophys., 26, 459-494, doi:10.1029/RG026i003p00459.

_ , and C. S. Frederiksen, 2007: Interdecadal changes in Southern Hemisphere winter storm track modes. Tellus, 59A, 599617, doi:10.1111/j.1600-0870.2007.00264.x.

Grose, M., B. Timbal, L. Wilson, J. Bathols, and D. Kent, 2015: The subtropical ridge in CMIP5 models, and implications for projections of rainfall in southeast Australia. Aust. Meteor. Oceanogr. J., 65, 90-106. [Available online at http://www. climatechangeinaustralia.gov.au/media/ccia/2.1.5/cms_page_media/ 472/Grose \%20etal\%202015\%20AMOJ\%2065\%202.pdf.]

Hawkins, E., and R. Sutton, 2009: The potential to narrow uncertainty in regional climate predictions. Bull. Amer. Meteor. Soc., 90, 1095-1107, doi:10.1175/2009BAMS2607.1.

—, and — 2011: The potential to narrow uncertainty in projections of regional precipitation change. Climate Dyn., 37, 407-418, doi:10.1007/s00382-010-0810-6.

Hope, P., and Coauthors, 2015: Seasonal and regional signature of the projected southern Australian rainfall reduction. Aust. Meteor. Oceanogr. J., 65, 54-71. [Available online at http:// www.climatechangeinaustralia.gov.au/media/ccia/2.1.5/cms_page_ media/472/Hope\%20etal\%202015\%20AMOJ\%2065_1.pdf.] 
Hoskins, B. J., and P. J. Valdes, 1990: On the existence of storm-tracks. J. Atmos. Sci., 47, 1854-1864, doi:10.1175/ 1520-0469(1990)047<1854:OTEOST>2.0.CO;2.

IPCC, 2013: Summary for policymakers. Climate Change 2013: The Physical Science Basis, T. F. Stocker et al., Eds., Cambridge University Press, 1-29.

Jun, M., R. Knutti, and D. W. Nychka, 2008: Spatial analysis to quantify numerical model bias and dependence: How many climate models are there? J. Amer. Stat. Assoc., 103, 934-947, doi:10.1198/016214507000001265.

Kalnay, E., and Coauthors, 1996: The NCEP/NCAR 40-Year Reanalysis Project. Bull. Amer. Meteor. Soc., 77, 437-471, doi:10.1175/1520-0477(1996)077<0437:TNYRP>2.0.CO;2.

Kidston, J., and E. P. Gerber, 2010: Intermodel variability of the poleward shift of the austral jet stream in the CMIP3 integrations linked to biases in 20th century climatology. Geophys. Res. Lett., 37, L09708, doi:10.1029/2010GL042873.

Knutti, R., R. Furrer, C. Tebaldi, J. Cermak, and G. A. Meehl, 2010: Challenges in combining projections from multiple climate models. J. Climate, 23, 2739-2758, doi:10.1175/ 2009JCLI3361.1.

Kobayashi, S., and Coauthors, 2015: The JRA-55 Reanalysis: General specifications and basic characteristics. J. Meteor. Soc. Japan, 93, 5-48, doi:10.2151/jmsj.2015-001.

Nguyen, H., A. Evans, C. Lucas, I. Smith, and B. Timbal, 2013: The Hadley circulation in reanalyses: Climatology, variability, and change. J. Climate, 26, 3357-3376, doi:10.1175/ JCLI-D-12-00224.1.

Paciorek, C. J., J. S. Risbey, V. Ventura, and R. D. Rosen, 2002: Multiple indices of Northern Hemisphere cyclone activity, winters 1949-99. J. Climate, 15, 1573-1590, doi:10.1175/ 1520-0442(2002)015<1573:MIONHC > 2.0.CO;2.

Pepler, A. S., L. V. Alexander, J. P. Evans, and S. C. Sherwood, 2016: Zonal winds and southeast Australian rainfall in global and regional climate models. Climate Dyn., 46, 123-133, doi:10.1007/s00382-015-2573-6.

Phillips, N. A., 1951: A simple three-dimensional model for the study of large-scale extratropical flow patterns. J. Meteor., 8, 381-394, doi:10.1175/1520-0469(1951)008<0381:ASTDMF>2.0.CO;2; Corrigendum, 9, 78, doi:10.1175/1520-0469(1952)009<0079: $\mathrm{C}>2.0 . \mathrm{CO} ; 2$.

Reifen, C., and R. Toumi, 2009: Climate projections: Past performance no guarantee of future skill? Geophys. Res. Lett., 36, L13704, doi:10.1029/2009GL038082.
Risbey, J. S., and P. H. Stone, 1996: A case study of the adequacy of GCM simulations for input to regional climate change assessments. J. Climate, 9, 1441-1467, doi:10.1175/ 1520-0442(1996)009<1441:ACSOTA > 2.0.CO;2.

_ , and T. J. O'Kane, 2011: Sources of knowledge and ignorance in climate research. Climatic Change, 108, 755-773, doi:10.1007/ s10584-011-0186-6.

_ , P. J. Lamb, R. L. Miller, M. C. Morgan, and G. H. Roe, 2002: Exploring the structure of regional climate scenarios by combining synoptic and dynamic guidance and GCM output. J. Climate, 15, 1036-1050, doi:10.1175/1520-0442(2002)015<1036: ETSORC $>2.0 . \mathrm{CO} ; 2$.

_ M. J. Pook, and P. C. McIntosh, 2013: Spatial trends in synoptic rainfall in southern Australia. Geophys. Res. Lett., 40, 3781-3785, doi:10.1002/grl.50739.

Schaller, N., I. Mahlstein, J. Cermak, and R. Knutti, 2011: Analyzing precipitation projections: A comparison of different approaches to climate model evaluation. J. Geophys. Res., 116, D10118, doi:10.1029/2010JD014963.

Simpson, I. R., T. A. Shaw, and R. Seager, 2014: A diagnosis of the seasonally and longitudinally varying midlatitude circulation response to global warming. J. Atmos. Sci., 71, 2489-2515, doi:10.1175/JAS-D-13-0325.1.

Taylor, K. E., R. J. Stouffer, and G. A. Meehl, 2012: An overview of CMIP5 and the experiment design. Bull. Amer. Meteor. Soc., 93, 485-498, doi:10.1175/BAMS-D-11-00094.1.

Tebaldi, C., and R. Knutti, 2007: The use of the multi-model ensemble in probabilistic climate projections. Philos. Trans. Roy. Soc. London, 365A, 2053-2075, doi:10.1098/rsta.2007.2076.

Tibaldi, S., and F. Molteni, 1990: On the operational predictability of blocking. Tellus, 42A, 343-365, doi:10.1034/ j.1600-0870.1990.t01-2-00003.x.

Timbal, B., and W. Drosdowsky, 2013: The relationship between the decline of southeastern Australian rainfall and the strengthening of the subtropical ridge. Int. J. Climatol., 33, 1021-1034, doi:10.1002/joc.3492.

Van Vuuren, D. P., and Coauthors, 2011: The representative concentration pathways: An overview. Climatic Change, 109, 5-31, doi:10.1007/s10584-011-0148-z.

Whetton, P., and Coauthors, Eds., 2015: Climate change in Australia: Projections for Australia's NRM regions. CSIRO Tech. Rep., 222 pp. [Available online at http://www.climatechangeinaustralia.gov. au/media/ccia/2.1.5/cms_page_media/168/CCIA_2015_NRM_ TechnicalReport_WEB.pdf.] 